\title{
Effect of Trailing Edge Flow Injection on Fan Noise and Aerodynamic Performance
}

\author{
E. Brian Fite ${ }^{1}$ and Richard P. Woodward ${ }^{2}$ and Gary G. Podboy ${ }^{3}$ \\ NASA Glenn Research Center, Cleveland, Ohio, 44135
}

\begin{abstract}
An experimental investigation using trailing edge blowing for reducing fan rotor/guide vane wake interaction noise was completed in the NASA Glenn 9- by 15-foot Low Speed Wind Tunnel. Data were acquired to measure noise, aerodynamic performance, and flow features for a 22" tip diameter fan representative of modern turbofan technology. The fan was designed to use trailing edge blowing to reduce the fan blade wake momentum deficit. The test objective was to quantify noise reductions, measure impacts on fan aerodynamic performance, and document the flow field using hot-film anemometry. Measurements concentrated on approach, cutback, and takeoff rotational speeds as those are the primary conditions of acoustic interest. Data are presented for a $2 \%$ (relative to overall fan flow) trailing edge injection rate and show a $2 \mathrm{~dB}$ reduction in Overall Sound Power Level (OAPWL) at all fan test speeds. The reduction in broadband noise is nearly constant and is approximately $1.5 \mathrm{~dB}$ up to $20 \mathrm{kHz}$ at all fan speeds. Measurements of tone noise show significant variation, as evidenced by reductions of up to $6 \mathrm{~dB}$ in the $2 \mathrm{BPF}$ tone at $6700 \mathrm{rpm}_{\mathrm{c}}$ and increases of nearly $2 \mathrm{~dB}$ for the 4 BPF tone at approach speed. Aerodynamic performance measurements show the fan with $2 \%$ injection has an overall efficiency that is comparable to the baseline fan and operates, as intended, with nearly the same pressure ratio and mass flow parameters. Hot-film measurements obtained at the approach operating condition indicate that mean blade wake filling in the tip region was not as significant as expected. This suggests that additional acoustic benefits could be realized if the trailing edge blowing could be modified to provide better filling of the wake momentum deficit. Nevertheless, the hot-film measurements indicate that the trailing edge blowing provided significant reductions in blade wake turbulence. Overall, these results indicate that further work may be required to fully understand the proper implementation of injecting flow at/near the trailing edge as a wake filling strategy. However, data do support the notion that noise reductions can be realized not only for tones but perhaps more importantly, also for broadband. Furthermore, the technique can be implemented without adversely effecting overall fan aerodynamic performance.
\end{abstract}

\section{Nomenclature}

$\mathrm{PR}=$ pressure ratio, $\frac{P_{t 2}}{P_{t 1}}$ ratio of downstream fan total pressure to free stream total pressure
$\mathrm{TR}=$ temperature ratio, $\frac{T_{t 2}}{T_{t 1}}$ ratio of downstream fan total temperature to free stream total temperature, ${ }^{\circ} \mathrm{R}$

Subscripts

$\mathrm{t}=$ Total pressure or temperature

$1=$ Upstream conditions

$2=$ Downstream conditions

c $=$ Corrected to standard day conditions

\footnotetext{
${ }^{1}$ Aerospace Engineer, Acoustics Branch, 21000 Brookpark Rd./54-3, Cleveland, OH, AIAA Member

${ }^{2}$ Aerospace Engineer, Acoustics Branch, 21000 Brookpark Rd./54-3, Cleveland, OH, AIAA Member.

${ }^{3}$ Aerospace Engineer, Acoustics Branch, 21000 Brookpark Rd./54-3, Cleveland, OH, AIAA Member
} 


\section{Introduction}

Due to the complexity of turbofan engines and the multitude of noise sources, there are many concepts for noise reduction. These include concepts that reduce noise at the source, absorb radiated noise (such as liners), or actively cancel noise. Flow control, in terms of turbomachinery, has been investigated for various purposes including

performance enhancement ${ }^{1,2}$, range extension ${ }^{3,4}$, and noise reduction ${ }^{5,6,7,8,9}$. With regard to noise reduction, one flow control concept being studied is fan wake management. This concept attempts to manage the low momentum fluid in the fan blade wakes caused by viscous losses on the airfoil. Mitigation can involve suction to remove low momentum fluid or flow injection to energize the wake and fill in the momentum deficit. More specifically, fan trailing edge blowing (FTEB) is one concept used to reduce fan exit guide vane (FEGV) noise at the source by filling the wake deficit created by the upstream fan before it impacts the stator.

Spectral analysis of the flow exiting fan blades in a high bypass turbofan show the bulk flow is comprised of both non-random, rotor-correlated components, as well as random elements, or flow turbulence. It is generally accepted that the rotor correlated components of the downstream flow generate tone noise while the random elements contribute to broadband noise generation. It logically follows that by modifying the wake characteristics, the noise generated can also be modified, and presumably reduced.

Significant work in the early 90 's by Brookfield and Waitz ${ }^{10,11}$ studied the implementation and effects of trailing edge blowing in a representative fan blade. Both suction and blowing were investigated, but most of their effort focused on blowing air out of the airfoil suction side surface near the trailing edge of the fan blade. .Measurements were made in a blow-down facility and showed that blowing could significantly alter the downstream wake characteristics. The facility used a $\mathrm{CO}_{2}$-Argon mixture to increase the density of the flow medium and thereby reduce the required fan rotational velocity simplifying the blade design. Additionally, high response data acquisition instrumentation was used to acquire aerodynamic data. Flow was channeled in the blade such that the injected air would match the deviation angle of the flow. The aerodynamic measurements from these experiments were encouraging and suggested potential noise benefits could be realized. Figure 1 displays a small fraction of their results but is representative and included here to show the potential impact of the blowing. The top curve clearly shows that the momentum deficit in the wake was partially filled; the second bar chart indicates that, using an FFT of the waveform, the expected harmonics from this wake should be reduced. This implied a potential reduction in tone noise. The bottom plot in Fig. 1 may be the most intriguing as it shows a notable reduction in the turbulence 
intensity not only in the wake region, but also in the passage flow. This indicated the potential for broadband noise reduction may also be realized.

The successful outcome of this work led to a test at NASA Glenn to measure the acoustic performance of trailing edge blowing using a low-speed test model in the Advanced Noise Control Fan (ANCF) ${ }^{12}$. A 48" tip diameter, low pressure ratio fan with trailing edge blowing was designed and tested. The large, low speed nature of the facility provided a favorable environment for the design and test of a fan with trailing edge blowing designed for continuous operation. This facility allowed direct measurement of the noise benefit; however, it was not possible to make aerodynamic performance measurements. The airfoil was designed to allow injection of air at the center of the blade trailing edge, while matching the deviation angle, and accommodate a range of flow rates provided by an air system integrally designed with the test rig. As part of the design process, acoustic tone predictions were completed using CFD generated wakes using the SWIFT ${ }^{13}$ code. These were supplied to an acoustic tone prediction tool, V072 $2^{14}$. During testing, the tones were measured in the ANCF facility using a NASA Glenn designed rotating rake ${ }^{15}$. A comparison of predicted and measured tone levels is shown in Fig. 2. The tone reductions are comparable although the V072 reductions are generally over-predicted. However, the overall noise reduction potential was encouraging even though not as high as predictions would indicate. The broadband noise impact was not measured since the broadband noise level generated by the model is controlled by the rotor; hence any rotor-stator broadband noise reductions would be masked. Additionally, no aerodynamic performance data were acquired as the very low fan pressure ratio precluded meaningful measurement of any efficiency changes using the trailing edge injection. Full results from these tests are reported in reference 16.

While the MIT work demonstrated effectiveness through aerodynamic measurements, and the ANCF results showed effectiveness through acoustic measurements, a comprehensive test was needed to fully investigate the performance of FTEB in a relevant environment. To further evaluate the effectiveness of trailing edge injection on wake mitigation, a new fan model was designed, called Rotor 9, which incorporated trailing edge flow injection. Considerable effort was expended to try and implement a blowing strategy that would provide equal or better aerodynamic performance while providing noise reduction through trailing edge flow injection. The fan was designed for use on the NASA Glenn UHB drive rig and was tested in the Glenn 9- by 15-Foot Low Speed Wind Tunnel $^{17}(9 \times 15)$, which has a test section capable of simulating appropriate aircraft test conditions for approach, cutback, and takeoff operation. Data were acquired for several blowing configurations; however, the focus of this 
paper will be on the nominal $2 \%$ trailing edge injection flow rate (defined as the ratio of fan trailing edge blowing (FTEB) flow / fan inlet flow), which was the design point. Far field acoustic data, aerodynamic performance data, and hot film data were acquired and will be discussed.

\section{Test Apparatus}

Scaled fan models designed and used by the Acoustics Branch at NASA Glenn are generally "modular," meaning that different configurations of the same basic hardware allow a variety of data to be acquired using the fewest parts to minimize costs. Specifically, aerodynamic performance, operability, acoustics (both far-field and modal), and flow diagnostic data can all be acquired in the same wind tunnel facility. The fan model in this test was powered by a $5000 \mathrm{HP}$ air driven turbine. A rotating balance was used to measure torque and thrust of the fan rotor. A flow system was designed to provide air for the trailing edge injection which allowed adjustment of both the flow rate and the span wise distribution of the blowing air using replaceable inserts in the bottom of each airfoil (see Fig. 4 and Fig. 5). It is worth noting the injection air is supplied by an external source and is not extracted from the core fluid as one might expect in a full-scale engine application. The test model was designed with configurations to acquire far-field acoustic data, aerodynamic performance data, and flow field velocity (using hot film and/or LDV), as well as accommodate a rotating microphone rake installation for measuring acoustic spinning modes. The fan for this test had a design tip speed of 840 feet per second and was designed to have identical performance metrics to a previously tested fan called Fan $1^{18}$ (see Table 1). Fan 1 was selected as the baseline to provide a fair comparison for FTEB, since a fan with no blowing would be thinner than Rotor 9. Rotor 9 was designed with added thickness to provide internal volume for the injection flow passages.

A picture of the test article is shown in Fig. 6, configured for far-field acoustic testing. The test section of the $9 \times 15$ is lined with acoustic treatment to prevent acoustic reflections and is anechoic to approximately $250 \mathrm{~Hz}$. A traversing microphone system is used to acquire far-field acoustic data at user-defined increments (for this test, 48 traverse stops), that are used to measure the sound directivity. The performance configuration (Fig. 7) used a bellmouth inlet for accurate total mass flow measurement, together with either a variable fan exit nozzle (VFEN)(allows fan mapping) or fixed area, flight type nozzle (allows fixed operating line measurements). The hot film data was acquired using the bellmouth inlet and flight nozzle but with a different fan case to accommodate provisions for the actuator mounting at several axial model stations. Additionally, the model allowed the rotor-to- 
stator guide vane spacing to be varied. During the aerodynamic and acoustic performance tests the stator vanes were located 1.8 axial fan chords downstream of the rotor; while during hot-film testing the stators were further downstream at a location 2.6 axial fan chords downstream of the rotor.

\section{Results}

\section{A. Aerodynamic Results}

Since Rotor 9 was designed to match the performance parameters of Fan 1, it is prudent to know whether this was achieved to assess the validity of the acoustic comparisons. In particular, Rotor 9 should have the same flow and pressure rise characteristics while maintaining a high adiabatic efficiency. Combination rakes at STA 175.0 (Fig. 3) were used to measure the fan pressure and temperature rise. These rakes incorporated a total pressure and a total temperature probe at each of 10 radial stations along the rake as shown in Fig. 8. These rakes provided the data for calculating overall pressure rise along with radial profiles of bypass total pressure, total temperature, and efficiency. A ring of static pressures was located co-planar with the STA 175.0 probe axial location on both the outer diameter and inner diameter of the bypass duct. To assess the ability of Rotor 9 to operate acceptably, the fixed nozzle operating line was measured and is shown in Fig. 9. The operating line data for Fan 1 were acquired using the "original nozzle" which is the fixed nozzle designed for the baseline fan. Rotor 9 used a nozzle with slightly more exit area, specifically $1.45 \%$ larger. When flow is injected at the trailing edge, the inlet flow is reduced to maintain the same total flow at the exit nozzle (recall the injection flow is coming from an external source). Therefore, a larger nozzle area was used to adjust the fan inlet mass flow back to a value near the design intent. At low flows, the two fans operate on essentially identical operating lines, as is desired. At higher flows, there are minor differences in results but these are well within the bellmouth weight flow measurement error band estimated at $+/-1 \%$. These variations were acceptable, and so the Rotor 9 operating line performance was determined to essentially match that of Fan 1 .

Since noise generated by the FEGV is a result of unsteady loading, one would assume the radial pressure, or loading, distribution may also affect the generated noise levels. Therefore, the fan pressure and temperature profiles were also measured to compare span-wise fan loading. The design of Rotor 9 was intended to fill the wake and reduce noise generated by the fan exit guide vane which is located in the bypass duct; therefore, only the bypass duct profiles are shown. In general, considering the fan blades were designed using different tools and with different 
geometry constraints, and since Rotor 9 includes the trailing edge blowing slots, the profiles for total pressure, total temperature, and efficiency are all very similar. This is important since the goal was to design the two fans, one with and one without TEB, to have the same performance characteristics.

A comparison of total pressure data at approach, cutback, and takeoff operating conditions is shown in Fig. 9. Both fans operated with similar pressure ratio profiles at mid-span, but differences are evident in the tip region and also near the hub. The tip data indicate Fan 1 has a higher pressure rise at the tip relative to Rotor 9 . This trend is consistent at all three operating conditions. Near the hub, Rotor 9 has a higher pressure rise. Since both fans had similar operating line performance, this implies the lower tip performance of Rotor 9 is offset by the increased hub performance. A possible source of the loading difference near the hub is the gap required at the base of Fan 1 to accommodate the variable pitch capability used in the Fan 1 design. This gap causes leakage around the blade root and impacts loading and flow quality at the root of the fan. Rotor 9 was a fixed pitch design and therefore had no root gap. With regard to tip loading, this may be influenced by differences in the flow paths. Again, Fan 1 being a variable pitch design required a matching spherical tip geometry for the fan and rub strip. The fan case for Rotor 9 used a constant diameter (cylindrical) over the rub strip for ease of manufacture and assembly. Both fans used the same abradable material, similar to material used on flight engines, for fan blade damage mitigation in the event of a fan rub.

The total temperature profiles are plotted for the same three operating conditions of approach, cutback, and takeoff in Fig. 10 for both Fan 1 and Rotor 9. At approach operating condition, Rotor 9 shows a higher temperature rise than Fan 1 near the tip. This tip trend is also present at the cutback operating condition, but Rotor 9 also has a higher temperature rise near the hub at the innermost measurement location. At takeoff speed, the trends observed at cutback remain but are larger in magnitude. Aside from these differences at the hub and tip, the temperature rise over most of the blade span for both fans is nearly identical for all three operating conditions.

Finally, the fan adiabatic efficiency profile for both fans is shown in Fig. 11 for approach, cutback, and takeoff conditions. Adiabatic efficiency is calculated as,

$$
\eta_{a d}=\frac{P R^{7 / 2}-1}{T R-1}
$$


As such, efficiency is a sensitive parameter in highlighting small pressure and temperature differences. It is important to note that the efficiency for these fans, both being low pressure-ratio and moderate tip speed designs, is very high. As a result, accurate measurement of efficiency is difficult since the fan temperature rise was small. This is evident in Fig. 11 where measurements at radii of 6.924" and 7.577" show efficiencies near 100\%. Even though the absolute efficiency is difficult to measure, relevant comparisons between Rotor 9 and Fan 1 are still possible by looking at the efficiency delta between the fans. Fan 1 shows improved efficiency near the tip with a value of $79.7 \%$ vs. $72.8 \%$ for Rotor 9 . However, near the hub, Rotor 9 efficiency is higher with a value of $93.1 \%$ vs. $89.7 \%$ for Fan 1. At mid-span locations, the fan efficiencies are comparable with Rotor 9 measuring approximately $97 \%$ and Fan 1 measuring $98.9 \%$. Given the difficulty in accurately measuring efficiency for this class of fan, the performance levels were considered similar for the purposes of this experiment.

Since the fans operated on nearly identical measured operating lines, an important global measure of the similarity of the two fan designs, the comparison of Rotor 9 performance to that of Fan 1 in terms of acoustics is considered valid. The nearly matching pressure ratio and temperature ratio radial profiles of the two fans are further evidence that this experiment is a fair assessment of FTEB; there were no variations in the aerodynamic performance parameters that could influence the overall acoustic performance outside of the use of trailing edge blowing.

\section{B. Acoustic Results}

Far-field acoustic data were taken with a translating sideline microphone probe and three fixed downstream microphone as shown in Fig. 13. The translating microphone probe was at an 89 inch sideline and acquired data at 48 discrete positions. The acoustic data were acquired as 5.9 and $59 \mathrm{~Hz}$ spectra. These spectral results were converted to lossless data by correcting for atmospheric attenuation and microphone response. Additional distance corrections were required for the downstream fixed microphones. The atmospheric absorption corrections included a frequency Doppler shift to account for the 0.10 Mach tunnel flow. Sound power level (PWL) spectra were calculated from the SPL spectra assuming spherical symmetry through the range of sideline data acquisition. Possible noise

contributions outside the sideline range were ignored. Sideline angles are presented as emission angles relative to the fan rotation axis for Mach 0.1 tunnel flow, and range from 25 to $158^{\circ}$. 
Rotor trailing edge blowing reduced both spectral rotor/stator interaction tones and broadband levels. Acoustic results showed that the maximum benefit from trailing edge blowing (TEB, relative to baseline Fan 1) was with full span blowing utilizing $2.0 \%$ of the fan bypass airflow heated to approximately bypass stream temperature. Figure 14 shows the Overall Sound Power Level (OAPWL) calculated from 1 to $50 \mathrm{kHz}$ as a function of corrected rotor $\mathrm{rpm}_{\mathrm{c}}$. The OAPWL, of course, includes contributions from all noise sources. Figure 14 shows that $2.0 \%$ trailing edge blowing results in a $2 \mathrm{~dB}$ overall noise reduction at all fan test speeds.

Figure 14 shows the Sound Power Level (PWL) for the $2^{\text {nd }}$ through $4^{\text {th }}$ rotor/stator interaction tones. This fan stage satisfied the rotor/stator cut-off criterion of reference ${ }^{19}$ such that the first tone order (BPF) is suppressed. Trailing edge blowing had little effect on the $2 \mathrm{BPF}$ tone at fan speeds below $6000 \mathrm{rpm}_{\mathrm{c}}$, however this tone was reduced by $6 \mathrm{~dB}$ at $6700 \mathrm{rpm}_{\mathrm{c}}$ with more modest reductions of 3 to $4 \mathrm{~dB}$ at higher fan speeds. The 3BPF tone level showed the most benefit from TEB at lower fan speeds, with a $5 \mathrm{~dB}$ reduction at $5425 \mathrm{rpm}_{\mathrm{c}}$ but essentially no change at $7525 \mathrm{rpm}_{\mathrm{c}}$ and higher speeds. The 4BPF tone showed only a slight reduction with TEB.

Figure 15 shows constant $59 \mathrm{~Hz}$ bandwidth spectra at three fan speeds. These spectra clearly show the benefit of 2.0\% TEB for reducing both interaction tone and broadband noise levels. These interaction tone levels in Fig. 15 are consistent with those of the previous figure. The spectra of Fig. 15 also show that TEB is beneficial for reducing broadband noise levels - especially at lower frequencies.

Figure 16 through Fig. 19 show Sound Pressure Level (SPL) directivities taken from $59 \mathrm{~Hz}$ constant bandwidth spectra. Directivities are shown for the $2 \mathrm{BPF}$ through $4 \mathrm{BPF}$ interaction tones and also for an arbitrary representative broadband level taken between the 2 and 3BPF tones. These four directivity plots are repeated for the designated approach condition, $5425 \mathrm{rpm}_{\mathrm{c}}$ (Fig. 16); $6700 \mathrm{rpm}_{\mathrm{c}}$ (Fig. 17); designated cutback fan speed, $7525 \mathrm{rpm}_{\mathrm{c}}$ (Fig. 18); and designated takeoff, $8750 \mathrm{rpm}_{\mathrm{c}}$ (Fig. 19). The tone level directivities at approach fan speed $\left(5425 \mathrm{rpm}_{\mathrm{c}}\right.$, Fig. 16) are consistent with the spectral results of Fig. 15. The spectral results showed essentially no TEB benefit for the 2BPF tone. The corresponding $2 \mathrm{BPF}$ directivities show that TEB had a mixed effect on this tone level, with noise reductions at a particular sideline angle being cancelled out by noise increases at other angles. The 3BPF tone was clearly reduced by TEB at this fan speed. The 3BPF tone directivity is somewhat unusual in that there is a forward and aft region of higher tone noise where TEB was most effective. TEB actually increased the 4BPF tone level at most sideline angles. TEB was effective in reducing the 2 through $4 \mathrm{BPF}$ tone levels at $6700 \mathrm{rpm}_{\mathrm{c}}$ (Fig. 15 through 
Fig. 17), showing noise reductions of $6 \mathrm{~dB}$ or more for the 2 and 3BPF tones over a significant span of sideline angles.

There was a significant tone, of unknown origin, in the reference Fan 1 spectra near designated cutback rotational speed $\left(7525 \mathrm{rpm}_{\mathrm{c}}\right)$. This very strong tone first appeared around $1 \mathrm{kHz}$, with a significant number of harmonics at higher frequencies. This Fan 1 spectral anomaly was seen in all Fan 1 results, including a later rebuild/testing of that fan. Consequently, it was not possible to calculate an overall sound power level for Fan 1 at this speed (note omission of Fan 1 data point in Fig. 13), nor was it desirable to include the Fan 1 spectra at cutback speed in this report. However, it was possible to extract $59 \mathrm{~Hz}$ bandwidth interaction tone levels from the Fan 1 spectra at cutback speed (first shown in Fig. 14), as well as a representative broadband level. Figure 18 shows these tone and broadband directivities at $7525 \mathrm{rpm}_{\mathrm{c}}$. Figure 18 shows that TEB is of some benefit for reducing the 2 through 4BPF tone level at the designated cutback fan speed.

The PWL spectra of Fig. 15 at design fan speed showed that only the 2 BPF tone clearly benefited from TEB. The corresponding directivities of Fig. 19 show that the $2 \mathrm{BPF}$ tone reduction associated with TEB was significant at more forward sideline angles. TEB showed little benefit for the 3BPF tone. The TEB effect on the 4BPF tone varied with sideline angle, with no overall noise reduction.

Wake filling properties of TEB address two fan noise mechanisms. Reductions in the wake defect are expected to give reductions in rotor/stator interaction tone levels. Fan broadband noise is thought to relate to flow turbulence levels, so reductions in rotor downstream turbulence would be expected to somewhat reduce broadband noise levels. The preceding far-field acoustic analysis has shown that TEB can, with the proper flow rate, reduce both of these fan noise mechanisms. The following section on rotor downstream flow surveys will quantify how TEB modified the rotor wake, resulting in the observed far-field noise reductions.

\section{Hot-film}

Detailed measurements of the fan wake flow fields generated downstream of Fan 1 and Rotor 9 with full-span blowing (hereafter referred to as TEB) were obtained at the two different axial locations depicted in Fig. 21. The upstream axial location corresponds to that of the Station 12.5 pressure/temperature rakes which were used in the aerodynamic performance phase of the test; the downstream axial location corresponds to what was the leading edge location of the stator vanes during the far-field acoustic and aerodynamic performance tests. During the hot-film testing, the stator vanes were moved downstream in the bypass duct to the location depicted in Fig. 21 so that the 
stators would not interfere with the radial translation of the hot-film probes. Radial surveys were conducted by sequentially indexing the hot-film probes to fifty, equally-spaced radial locations in each of the two axial planes depicted in Fig. 21.

The hot-film measurements were made using dual-sensor, TSI model 1246-20, cross-film probes. The cross-film designation stems from the $\mathrm{x}$-pattern formed by the two sensors when viewed from a direction above and perpendicular to the two parallel planes containing the sensors. A cross-film probe allows the flow angle within the plane of the x-pattern to be measured. During this test, two different types of probes were used; one had the sensors oriented to measure the total velocity and the yaw (swirl) angle in the wake flow; the other type had the sensors oriented to measure the total velocity and the radial flow angle. Surveying at the same point in the flow field using both probes provides a measure of the yaw flow angle, the radial (pitch) flow angle, and two independent measurements of the total velocity.

Data were acquired using a DataMAX data acquisition system. The DataMAX was set to record the voltages output by the two hot-film sensors and the once-per-revolution signal from the model. Each of the three signals was sampled at a $200 \mathrm{kHz}$ sampling rate and filtered using a low-pass filter set at $90 \mathrm{kHz}$. Data were acquired at each measurement location for three seconds. Pre-test dynamic calibrations were performed by inputting a square wave into each anemometer circuit and observing the response on an oscilloscope. These square wave tests indicate that the frequency response of each hot-film sensor/anemometer was approximately $40 \mathrm{kHz}$.

The objective of the hot-film testing was to measure the velocity fields generated by the two different configurations (Fan 1 and TEB) so that detailed, quantitative evaluations could be made regarding: 1) the ability of the TEB configuration to reduce the mean blade wake velocity deficit relative to the Fan 1 configuration, and 2) the reduction in blade wake turbulence, if any, associated with blowing (TEB) vs. no blowing (Fan 1). The intent was to use the detailed flow velocity data obtainable from the hot-film measurements to explain any noise differences between the two configurations. In a compressible, non-isothermal flow like that encountered during this experiment, however, where all the flow variables (pressure, temperature, density, and velocity) are changing from one point in the wake flow to another, it is difficult to accurately measure the velocity fields using thermal anemometry. The difficulty arises from the fact that the output of the hot-film probe is a function of more than just the velocity in the flow; the probe responds to anything in the flow which changes the amount of heat transferred away from the probe, and this includes all of the other flow variables in addition to the velocity. Therefore if one 
wants to measure the velocity, one needs to determine the effect these other variables have on the output of the probe and account (i.e. correct) for that effect, or demonstrate that the effect of the other variables is negligible in comparison to the effect of the changing velocity.

One way to measure the effect that one of the other flow variables - total temperature - has on the output of the probe is to use what is known as the dual-overheat-ratio technique. With this technique a probe is calibrated over a range of velocities and total temperatures at each of two different overheat ratios (i.e. at each of two different film operating temperatures). Then, during the experiment, data is acquired twice - once with the probe set at each of the two overheat ratios. In practice the dual-overheat-ratio technique doubles the amount of time required to obtain data, but it provides more information; it allows one to measure both the total temperature and the velocity in the flow, and it corrects the measured velocities by accounting for the total temperature variations in the flow. In essence, this dual-overheat-ratio method provides another equation to work with (two rather than one), and allows one to solve for two unknowns. In addition, the dual-overheat-ratio data can be processed in two different ways: 1) using the data obtained via both overheats to solve for both the total temperature and the velocity; and 2) using the data obtained from only one of the two overheats to determine the velocity, as if only single-overheat data were available. By comparing the velocities output by these two processing methods, one can determine the effect that correcting for the total temperature variations has on the measured velocities and whether or not such a correction is needed.

Due to a lack of time, most of the data obtained during this test were obtained using a single-overheat-ratio. Data were obtained at three different fan rotational speeds, corresponding to the approach $\left(5425 \mathrm{rpm}_{\mathrm{c}}\right.$ ), cutback (7525 $\left.\mathrm{rpm}_{\mathfrak{c}}\right)$ and take-off $\left(8750 \mathrm{rpm}_{\mathrm{c}}\right)$ operating conditions. The mean velocity data obtained from the single-overheat-ratio surveys were corrected for radial variations in total temperature and static pressure using mean (circumferentiallyaveraged) measurements of these quantities available from the pressure and temperature instrumentation within the bypass duct downstream of the fan. These mean velocity data could not, however, be corrected for circumferential variations in the static pressure and total temperature. The dual-overheat technique allows a correction for one of these, the circumferential variations in total temperature.

At the end of the test, a limited amount of data were obtained using the dual-overheat-ratio technique in order to determine the effect that the circumferential variations in total temperature had on the mean velocity measurements. Not surprisingly, these dual-overheat-ratio data indicate that the need to correct the mean velocity measurements for circumferential variations in total temperature increases as rotor speed increases. At the approach speed $\left(5425 \mathrm{rpm}_{\mathfrak{c}}\right)$, 
accounting for these variations had very little effect on the mean velocity wake profiles. This suggests that the approach condition single-overheat-ratio data acquired during the test could be used as is, without an applied correction. At the take-off condition, however, the correction supplied by the dual-overheat-ratio technique had a significant effect on the mean velocity profiles. This was unfortunate, since it demonstrates that all of the high speed data should have been acquired at two different overheats, not just the small amount obtained near the end of test. Lacking the dual-overheat-ratio measurements needed to correct the data, it is best not to use the high-speed singleoverheat data to make detailed, quantitative comparisons of the mean velocity wake profiles generated by Fan 1 and Rotor 9 with TEB. As such, this paper will only present low-speed, approach-condition data obtained using a singleoverheat-ratio. This data does not appear to require the correction for circumferential variations in total temperature.

As indicated earlier, the primary objective of the TEB rotor design effort was to partially fill in the mean blade wake downstream of the TEB fan relative to Fan 1 in order to reduce rotor-stator interaction tone noise. Figure 22 provides some indication as to the extent to which this goal was achieved. This figure shows a comparison of total velocities measured downstream of the TEB fan (left) and Fan 1 (right) at the upstream wake axial location (see Fig. 21) with the two fans operating at the approach condition $\left(5425 \mathrm{rpm}_{\mathrm{c}}\right)$. Both plots show average-passage data; i.e., the mean velocities measured downstream of the individual blade passages were folded into one passage and averaged as outlined in Ref. 20. The average-passage flow is shown repeated in the plots in order to show the variations in the flow across the boundaries of the passage. The view is from downstream-looking-upstream; the fan blades rotate clockwise in this view. These plots clearly show that TEB is having a significant effect on the blade wakes. There appear, however, to be some regions along the span of the wake where the blowing is having a beneficial effect (thinner, shallower wakes than the baseline) and other regions where the blowing is having an adverse effect (wider, deeper wakes). The regions of adverse effect are shown as isolated "islands" of low momentum flow at discreet locations along the span of the blade wake. As illustrated in Fig. 4 the TEB flow emanated from five separate slots located along the trailing edge of Rotor 9. The islands of low momentum flow depicted in the TEB contour plots are believed to occur downstream of the narrow, solid regions along the blade trailing edge which separate the slots. The exact origin of these low momentum regions is unclear; however, they may result from the interaction of the three merging flow streams - the two flows emanating from the adjacent slots and the external flow passing over the blade. 
More detailed comparisons of these blade wake flows are provided in Fig. 23. This figure shows six different sets of line plots (provided in parts $\mathrm{A}$ thru $\mathrm{F}$ of the figure). Each set corresponds to a different radial location in the flow; the locations are indicated by the solid lines overlaid on top of the contour plots shown above the line plots. In the line plots, the blue line shows the mean total velocity distribution measured downstream of the TEB fan, and the black line shows the distribution measured downstream of Fan 1. A discussion of each of the different parts of Fig. 23 is presented below:

Part A) The plot provided shows data obtained in the outer region of the flow at a radius of 9.74". This plot indicates that at this location TEB provides a slight reduction in the mean velocity deficit relative to Fan 1 . This plot, however, is not typical of the data obtained in the outer regions of the fan bypass duct. As explained earlier, data were acquired at 50 , equally-spaced radial locations along the span of the duct. Of the data obtained at the 19 outermost locations, the data provided here show the largest reduction in the mean velocity deficit. Surprisingly, most of the 19 other radial locations within this outer region show a deeper wake associated with the TEB fan.

Part B) This survey point corresponds to the radial location of one of the islands of low momentum flow mentioned in the discussion above. As can be seen in this plot, the mean wake deficit associated with TEB is deeper than that of the baseline rotor at this location.

Part C) Further inboard, the effects of blowing are more apparent. This part shows data obtained at a midspan location away from the islands of low momentum flow. A significant reduction in the mean blade wake occurs at this location. This indicates that the blowing is more effective in the mid-span region of the TEB fan than it is in the outer region.

Part D) This line plot shows data obtained further inboard at about $35 \%$ span. Once again the TEB appears to be effective at this location.

Part E) The data shown here were obtained at a radial location corresponding to the innermost island of low momentum flow. Unlike in the outer spans where such islands indicated a deeper wake for the TEB fan, here the deficit is roughly the same for TEB and Fan 1.

Part F) This data was obtained at a location in-between the innermost island of low momentum flow and the hub surface. This plot clearly shows that at this inboard location the wake is being over-filled. 
Overall, the above comparisons of wake data obtained at the approach condition indicate less-than-expected blade wake filling in the outer regions of the blade wakes and more-than-expected inboard. This, in turn, suggests that less air was being blown out of the trailing edge in the tip region than expected, and that more air was being blown out at the inner radial locations than expected.

As mentioned above, one reason for acquiring the hot-film data was to determine the extent to which TEB reduces the turbulence in the blade wakes. Fig. 24 shows a comparison of total turbulent velocities (defined as the standard deviation of the total velocities measured at a location in the flow) measured downstream of the TEB rotor (left) and Fan 1 (right) at the upstream axial measurement location with the fans operating at the approach condition $\left(5425 \mathrm{rpm}_{\mathrm{c}}\right)$. The rotor tip clearance flow is a distinctive feature in each of these plots. This flow shows up clearly in the contours of each fan as the region of turbulent flow which exists along the outer case between the blade wakes. As shown, the turbulence level in the tip flow generated by the TEB fan is higher. This difference is thought to stem from a difference in the loading of the two fans. Although the TEB rotor was designed to have the same overall loading as Fan 1, the span-wise loading distribution of the two fans was different. The TEB rotor was designed with more loading at the tip of the blade and less loading inboard. Although this was the design intent, the radial total pressure profiles presented in Fig. 8 indicate that the TEB fan was not very successful at converting this higher tip loading into an increase in total pressure. Instead, the Fig. 21 data suggest that the additional work done on the flow by the tip regions of the TEB blades was converted to an increase in flow turbulence.

Although the contours presented in Fig. 24 show higher turbulence levels downstream of the TEB rotor in the outer regions of the blade wakes, they show significantly lower turbulence levels inboard. The higher levels in the outer regions of the blade wakes associated with the TEB rotor may result from 1) the higher blade loading in the tip region and 2) the less-than expected level of TEB in this region suggested by the mean velocity measurements presented above. The span-wise trend (lower levels of turbulence associated with TEB with decreasing radius) correlates well with the apparent level of blowing along the blade span - as the blowing level increases the turbulence level decreases.

The line plots presented in Fig. 25 show some of this data in more detail. This figure shows comparisons of the total turbulent velocity distributions measured downstream of the two fans at four different radial locations. The magenta line shows the circumferential distribution of total turbulent velocity measured downstream of the TEB 
rotor; the black line shows Fan 1 data. The span of the $\mathrm{x}$-axis corresponds to one blade pitch. Each part of this figure is discussed below:

Part A) The data presented here correspond to a radial location which passes near the center of the tip flows developed by the two fans. This comparison shows higher turbulence levels downstream of the TEB rotor across the entire width of the passage. This suggests that the turbulence levels are higher not only in the tip flow but also in the blade wakes generated by the TEB fan at this outboard location.

Part B) The data shown in this part of the figure were acquired at a radius of 10.06". Here the turbulence level downstream of the two fans is essentially the same.

Part C) The Fig. 23 contour plots indicate that TEB generates less turbulence than Fan 1 inboard of about $75 \%$ span. The data shown in part $\mathrm{C}$ were obtained near $50 \%$ span. At this radial location the TEB rotor is generating significantly less turbulence than Fan 1.

Part D) This trend of increasing benefit (reduced turbulence) with decreasing radius continues as the hub is approached. The data shown here was obtained at about $25 \%$ span. At this location the peak turbulent velocity associated with TEB is about half of that of Fan 1.

These turbulent velocity comparisons indicate that TEB is very effective at reducing blade wake turbulence. This reduction is shown to correlate well with the level of blowing. In the tip region where the blowing was less-thanexpected, very little, if any, reduction in turbulence was achieved. In the mid-span and inner regions, however, where the level of blowing was higher, a significant reduction in the turbulence was achieved.

\section{Conclusion}

To assess the effect of fan blade wake thickness and turbulence velocities on acoustics, a fan called Rotor 9 was integrally designed to: 1) use trailing edge blowing to fill the wake momentum deficit; and 2) match the performance parameters of an existing fan called Fan 1 . The design parameters of the existing fan established the design parameters for Rotor 9, which were representative of a modern high-bypass, low pressure ratio fan design. These fans were tested and results presented for $2 \%$ trailing edge injection rate as a percentage of fan inlet flow for Rotor 9. The aerodynamic performance measurements indicate the design matches the baseline fan operating line very well. Detailed performance measurements for radial total pressure and temperature profiles further indicate that Rotor 9 performs substantially like Fan 1 in terms of spanwise loading distribution. More closely matched 
performance between the fans provides for an experiment that is better able to demonstrate the impact of trailing edge blowing on fan performance and noise without introducing other experimental variations that could alter the wake. Efficiency measurements made of these fans indicated that extreme care is required in the design of the measurement systems used to determine the efficiency of such low pressure ratio fans.

Far field acoustic results showed that $2.0 \%$ rotor trailing edge blowing provides a significant reduction in both rotor/stator interaction tone levels and broadband noise levels relative to the baseline fan. Trailing edge blowing reduced overall noise levels by about $2 \mathrm{~dB}$ throughout the range of test speeds. The trailing edge blowing benefit for interaction tones varied with fan speed and tone order; however, instances of tone noise reductions of $6 \mathrm{~dB}$ or more were observed. The observed global broadband noise reduction of up to $2 \mathrm{~dB}$ (especially at frequencies below $6 \mathrm{kHz}$ ) may be significant for future fan designs incorporating advanced stators designed for minimal interaction tone generation. In such a case, the advanced stators could target tone reductions while the TEB could target broadband. Furthermore, the use of a cut-on stator design would further improve broadband performance assuming the TEB and stator designs can mitigate the tone noise.

Detailed measurements of the fan wake flow fields generated downstream of the baseline Fan 1 rotor and Rotor 9 with full-span blowing were obtained using hot-film probes at two different axial locations and at three different rotor speeds corresponding to the approach, cutback, and takeoff operating conditions of the two fans. Because of inaccuracies associated with using thermal anemometry to measure flow velocities in high-speed, compressible, non-isothermal flows, only low-speed approach condition data have been presented. The objective of the hot-film testing was to measure the velocity fields generated by the two different configurations (baseline Fan 1 and TEB) so that detailed, quantitative evaluations could be made regarding: 1) the ability of the TEB configuration to reduce the mean blade wake velocity deficit relative to the baseline Fan 1 configuration; and 2) the reduction in turbulence, if any, associated with blowing (TEB) vs. no blowing (Fan 1). The approach condition data presented herein indicate that the extent to which the TEB configuration reduced the mean blade wake velocity deficit relative to Fan 1 varied with span-wise location. In the tip region the TEB configuration was not very effective at reducing the mean blade wake velocity deficit; in contrast, at the innermost radial locations the TEB resulted in overfilling of the mean wakes. These data suggest that the amount of air exiting the trailing edge was less-than-expected in the tip region and more-than-expected near the hub. Turbulence measurements made downstream of the two fans support this finding; the turbulence data show that the TEB configuration produced higher turbulence levels in the outer regions 
of the blade wakes, but lower levels inboard of about $75 \%$ span. At the innermost radial locations the turbulence levels with TEB were significantly lower than with the Fan 1 configuration. In this region, the highest turbulent velocities measured within the blade wakes with TEB were about half of those measured with Fan 1 . This reduction in blade wake turbulence may be responsible for the reduction in broadband noise indicated in the acoustic measurements.

In addition to details on the concept of FTEB, a test bed capability has been demonstrated at NASA Glenn that allows the testing of fans using various flow control systems. The system that supplied blowing air at various temperatures and flow rates for this test could also be used to apply blowing at other locations or to other components. Additionally, the system could be modified to apply suction rather than blowing. The impacts that such flow control schemes have on the aerodynamic performance, operability, and acoustics of the test article can all be measured in the Glenn 9x15 wind tunnel facility; in addition, thermal anemometry and laser Doppler velocimetry systems available at this facility can be used to establish a link between changes in the flow fields and changes in the aerodynamic and acoustic performance.

\section{Acknowledgments}

The authors would like to express appreciation for the contributions of the design and fabrication team who worked hard to make the components perform as desired to achieve the intended performance. Innovative designs and the use of rapid prototyping allowed several complex components to be fabricated in a cost effective manner and within reasonable schedules. In addition, the test team and test engineers who were part of the 9- by 15-foot wind tunnel test team worked diligently to install subsystems and get all of the test systems operational. Everyone involved showed dedication in getting the job done and allowing the test the best opportunity for success. Finally, support of the Quiet Aircraft Technology Program and Project offices to provide funding and support to encourage the team to complete the experimental assessment of this concept.

\section{References}

${ }^{1}$ Merchant, A., Kerrebrock, J. L., Adamczyk. J. J., and Braunscheidel, E., "Experimental Investigation of a High Pressure Ratio Aspirated Fan Stage," ASME Paper GT2004-53679, Sept, 2004. Also NASA TM-2004-213080. 
${ }^{2}$ Culley, D., Bright, M. M., Prahst, P. S., and Strazisar, A. J., "Active Flow Separation Control of a Stator Vane Using Surface Injection in a Multistage Compressor Experiment," ASME Paper GT2003-38863, June, 2003. Also NASA TM-2003212356.

${ }^{3}$ Strazisar, A. J., Bright, M. M., Thorp, S. Culley, D. E., and Suder, K. L., "Compressor Stall Control Through Endwall Recirculation," ASME Paper GT2004-54295, June, 2004.

${ }^{4}$ Hathaway, M. D., "Self Recirculating Casing Treatment Concept for Enhanced Compressor Performance," ASME Paper GT-2002-30368, July, 2002. Also NASA TM-2002-211569 or ARL-TR-2748.

${ }^{5}$ Naumann, R. G., "Control of Wake from a Simulated Blade by Trailing Edge Blowing," Master's Thesis, Lehigh University, Bethlehem, PA, 1992.

${ }^{6}$ Corcoran, T. E., “Control of Wake from a Simulated Blade by Trailing Edge Blowing,” Master's Thesis, Lehigh University, Bethlehem, PA, 1992.

${ }^{7}$ Halasz, C., Arntz, D., Burdisso, R., and Ng Wing, "Fan Flow Control for Noise Reduction Part 1: Advanced Trailing Edge Blowing Concepts," AIAA 2005-3025, May 2005.

${ }^{8}$ Langford, M. D., Minton, C. M., Ng, W. F., Estevadeordal, J., and Burdisso, R. A., "Fan Flow Control for Noise Reduction Part 2: Investigation of Wake Filling Techniques," AIAA 2005-3026, May 2005.

${ }^{9}$ Langford, M. D., Minton, C. M., Ng, W. F., Burdisso, R. A., and Halasz, C., "Fan Flow Control for Noise Reduction Part 3: Rig Testing of Optimal Design," AIAA 2005-3027, May 2005.

${ }^{10}$ Brookfield, J. M., “Turbofan Rotor/Stator Interaction Noise Reduction Through Trailing Edge Blowing,” Ph.D. Thesis, Massachusetts Institute of Technology, June 1998.

${ }^{11}$ Brookfield, J. M., and Waitz, I. A., "Trailing Edge Blowing for Reduction of Turbomachinery Fan Noise," AIAA Journal of Propulsion and Power, Volume 16, Number 1, 2000, pp.57-64.

${ }^{12}$ Sutliff, D., Loew, R., Lauer, J., and McAllister, J., "The Advanced Noise Control Fan," AIAA-2006-3150, June 2006.

${ }^{13}$ Chima, R. V., "Swift - Multiblock Analysis Code for Turbomachinery, User's Manual and Documentation," Version 300 , Sept. 2003.

${ }^{14}$ Meyer, H. D., and Envia, E., “Aeroacoustic Analysis of Turbofan Noise Generation, NASA CR-4715, 1996.

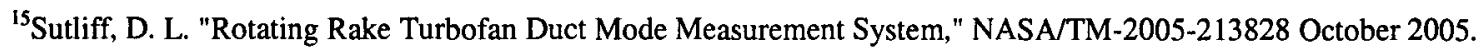

${ }^{16}$ Sutliff, D. L., Tweedt, D. L., Fite, E. B., and Envia, E., "Low-Speed Fan Noise Reduction With Trailing Edge Blowing," International Journal of Aeroacoustics, Vol. 1, No. 3, 2002.

${ }^{17}$ Soeder, R. H., NASA Lewis 9- by15-Foot Low-Speed Wind Tunnel User Manual. NASA TM 106247, 1993.

${ }^{18}$ Jeracki, R. J., "Comprehensive Report of Fan Performance from Duct Rake Instrumentation on 22-Inch Diameter, ADPType, Very Low Tip Speed Fan Models," NASA TM 2006- 213863, 2005. 
${ }^{19}$ Tyler, J. M. and Sofrin, T. G., “Axial Flow Compressor Noise Studies,” SAE Trans, Vol. 70, 1962, pp. 309-332.

${ }^{20}$ Podboy, G. G., Krupar, M. J., Helland, S. M., and Hughes, C. E., "Steady and Unsteady Flow Field Measurements Within a NASA 22-Inch Fan Model," AIAA-2002-1033, July 2003.

Table 1 Design Fan Performance Parameters

\begin{tabular}{|c|c|}
\hline Fan Parameter & $\begin{array}{c}\text { P\&W - NASA } \\
\text { Low Noise Fan } 1\end{array}$ \\
\hline \multicolumn{2}{|l|}{ Pressure Ratio } \\
\hline SLTO & 1.284 \\
\hline Cruise & 1.294 \\
\hline Approach & 1.077 \\
\hline Cutback & 1.209 \\
\hline \multicolumn{2}{|l|}{ Corrected rpm } \\
\hline SLTO & 8,750 \\
\hline Cruise & 8,400 \\
\hline Approach & 5,425 \\
\hline Cutback & 7,525 \\
\hline \multicolumn{2}{|l|}{ Corrected Tip Speed, $\mathrm{ft} / \mathrm{sec}$} \\
\hline SLTO & 840 \\
\hline Cruise & 806 \\
\hline Approach & 521 \\
\hline Cutback & 722 \\
\hline \multicolumn{2}{|l|}{ Corrected W/A, $\mathrm{lb}_{\mathrm{m}} / \mathrm{sec}^{*} \mathrm{ft}^{2}$} \\
\hline SLTO & 36.9 \\
\hline Cruise & 42.5 \\
\hline Approach & 22.7 \\
\hline Cutback & 33.3 \\
\hline Bypass Ratio - Cruise & 13.3 \\
\hline Blade Number & 18 \\
\hline Vane Number & 45 \\
\hline Hub/Tip & .426 \\
\hline Diameter - LE, in. & 22.0 \\
\hline
\end{tabular}



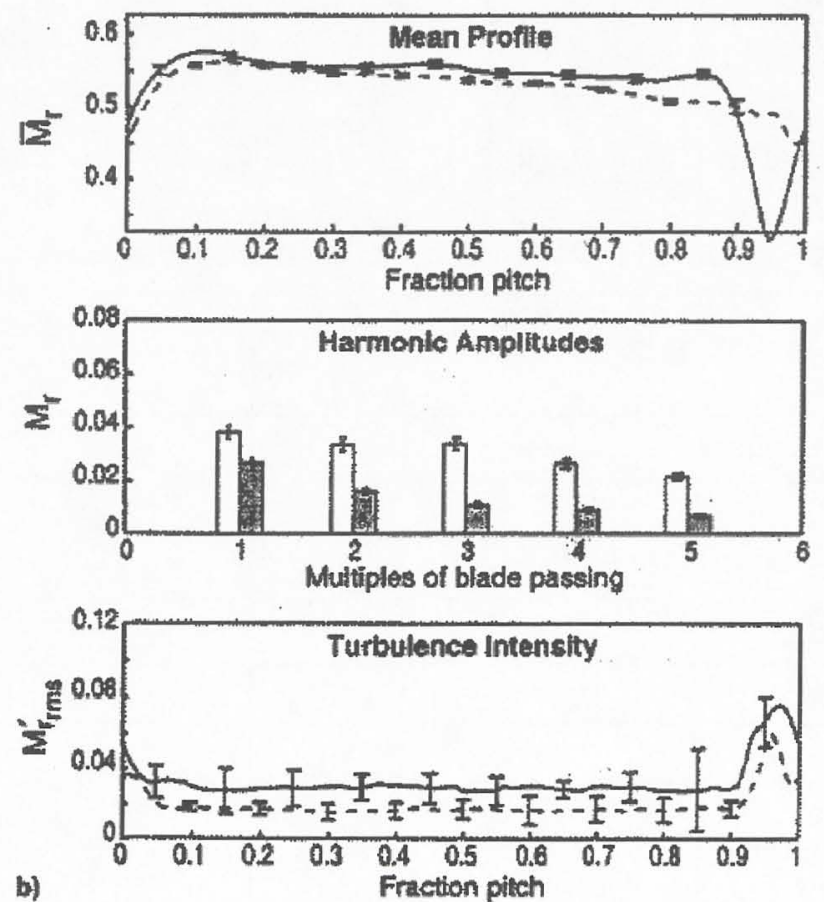

Fig. 1 Brookfield and Waitz results at 50\% span, .1 chord downstream, solid line no injection, dashed line $1.9 \%$ fan flow

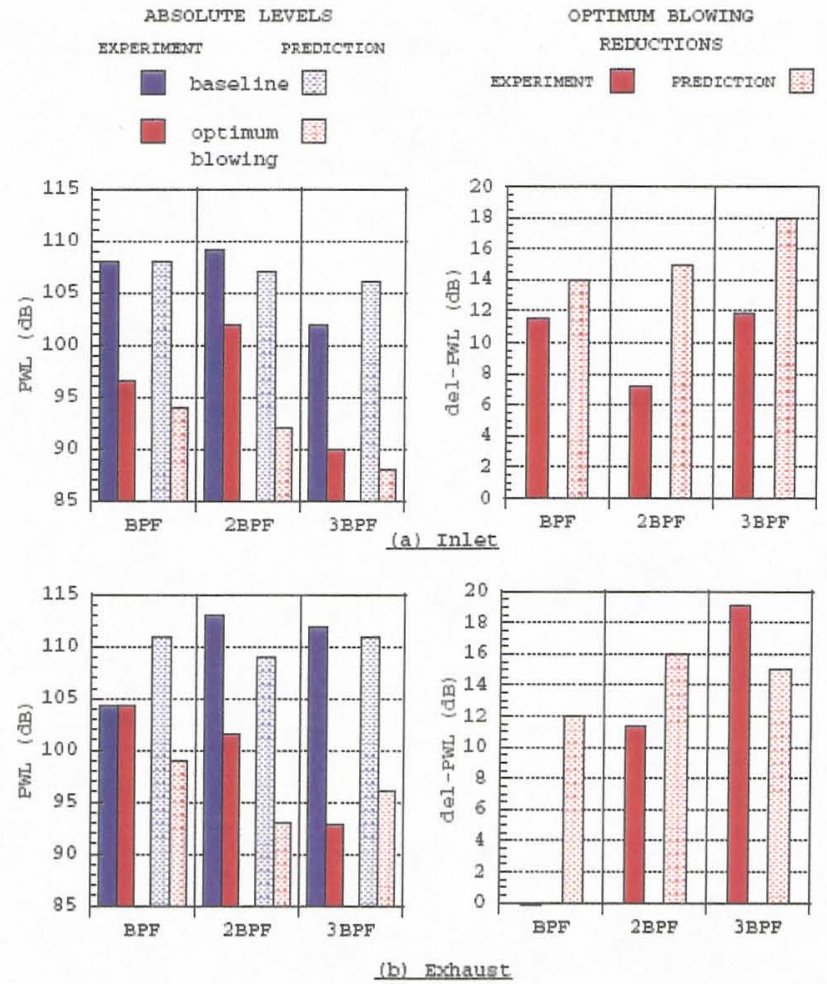

Fig. 2 Predicted and measured tone levels for ANCF Trailing Edge Injection 


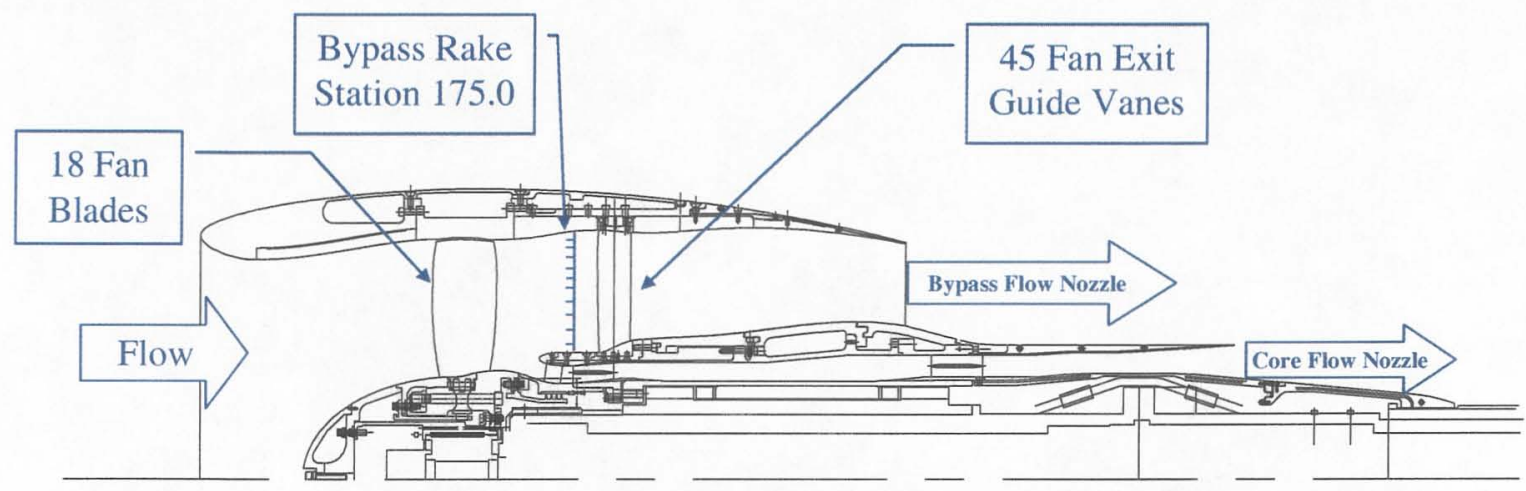

Fig. 3 Model Hardware Typical Cross Section

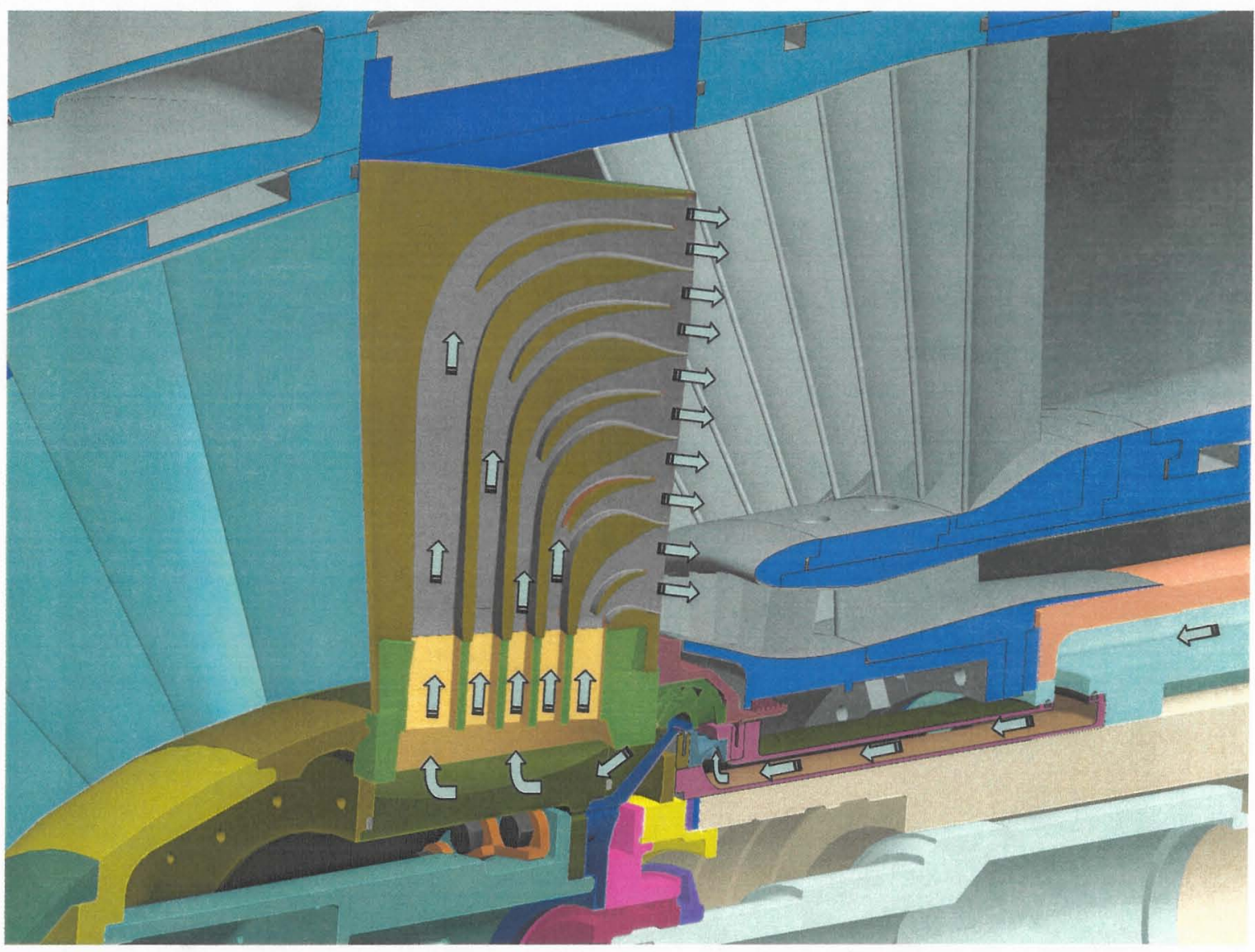

Fig. 4 Trailing Edge Air Injection \& Supply 


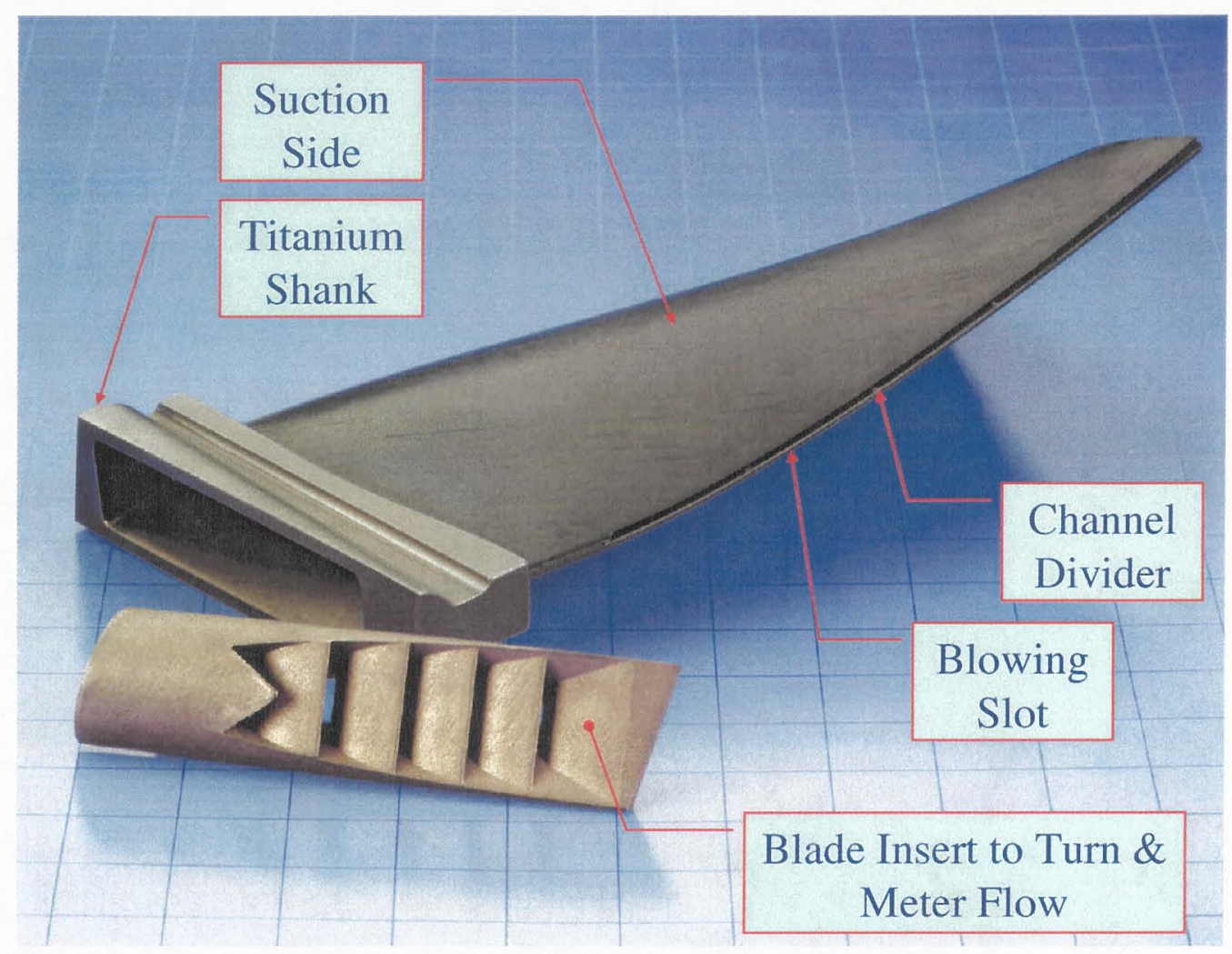

Fig. 5 Rotor 9 fan blade design with trailing edge blowing.

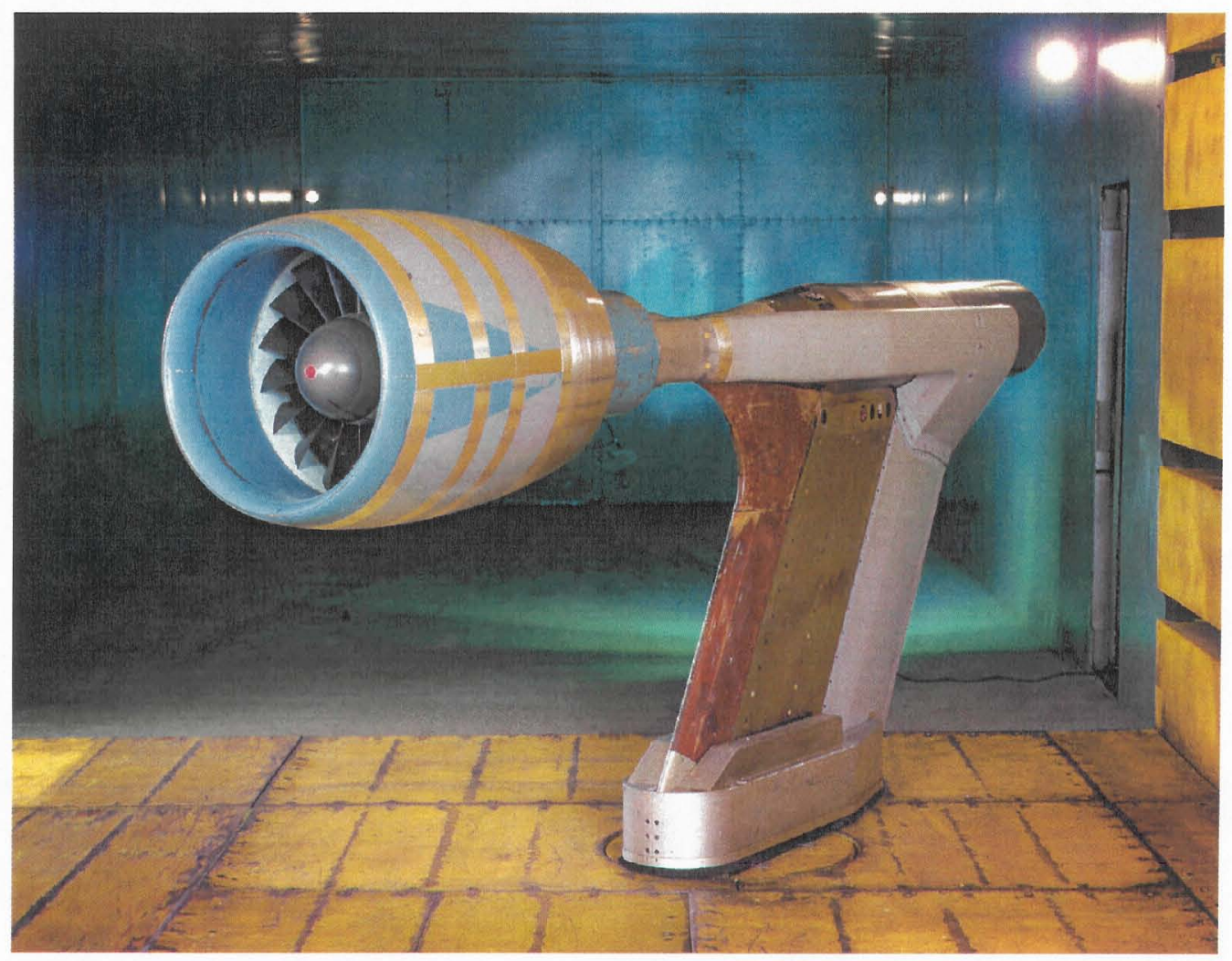

Fig. 6 Model in far-field acoustic configuration. 


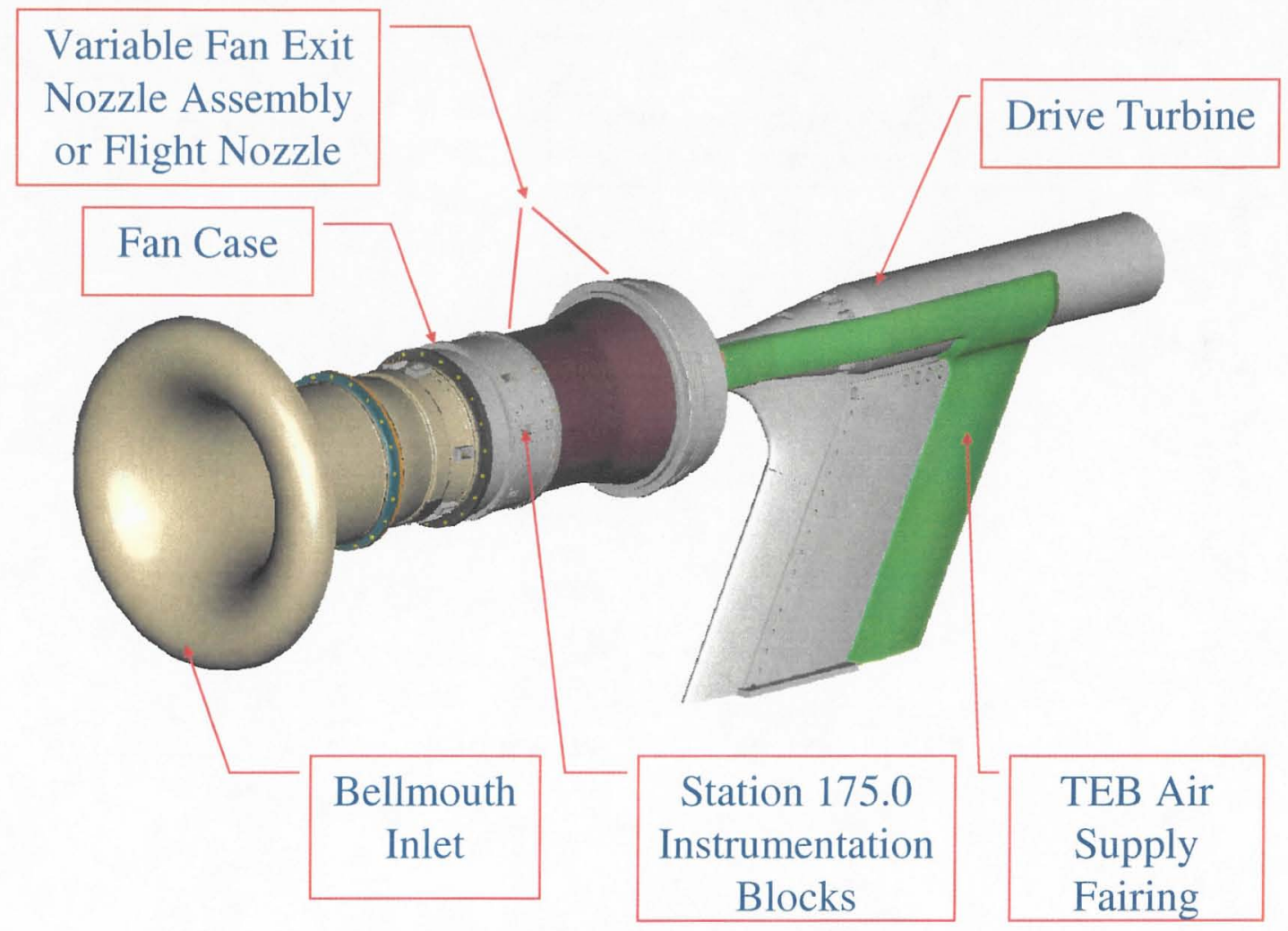

Fig. 7 Model in performance configuration

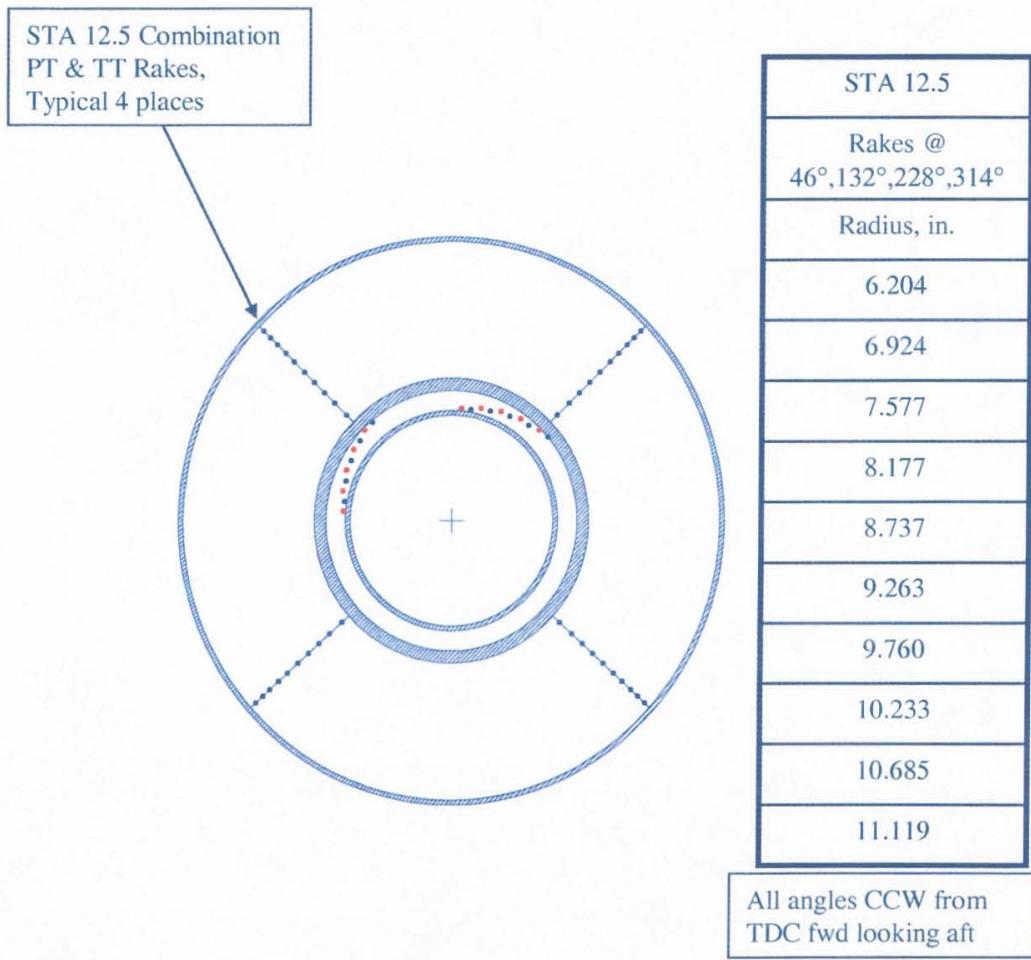

Fig. 8 Station 175.0 combination rake measurement locations. 


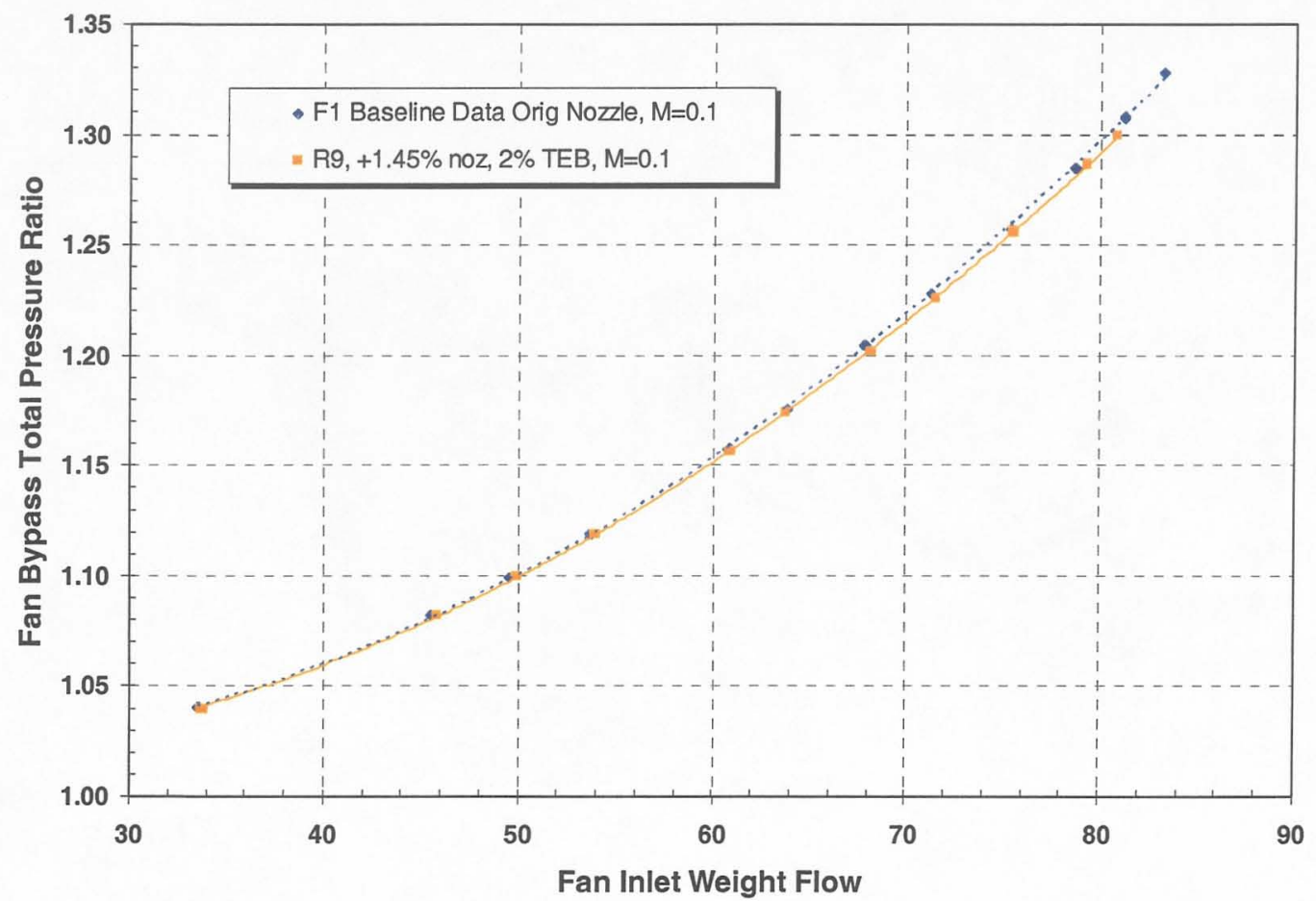

Fig. 9 Rotor 9 operating line compared to baseline fan operating line

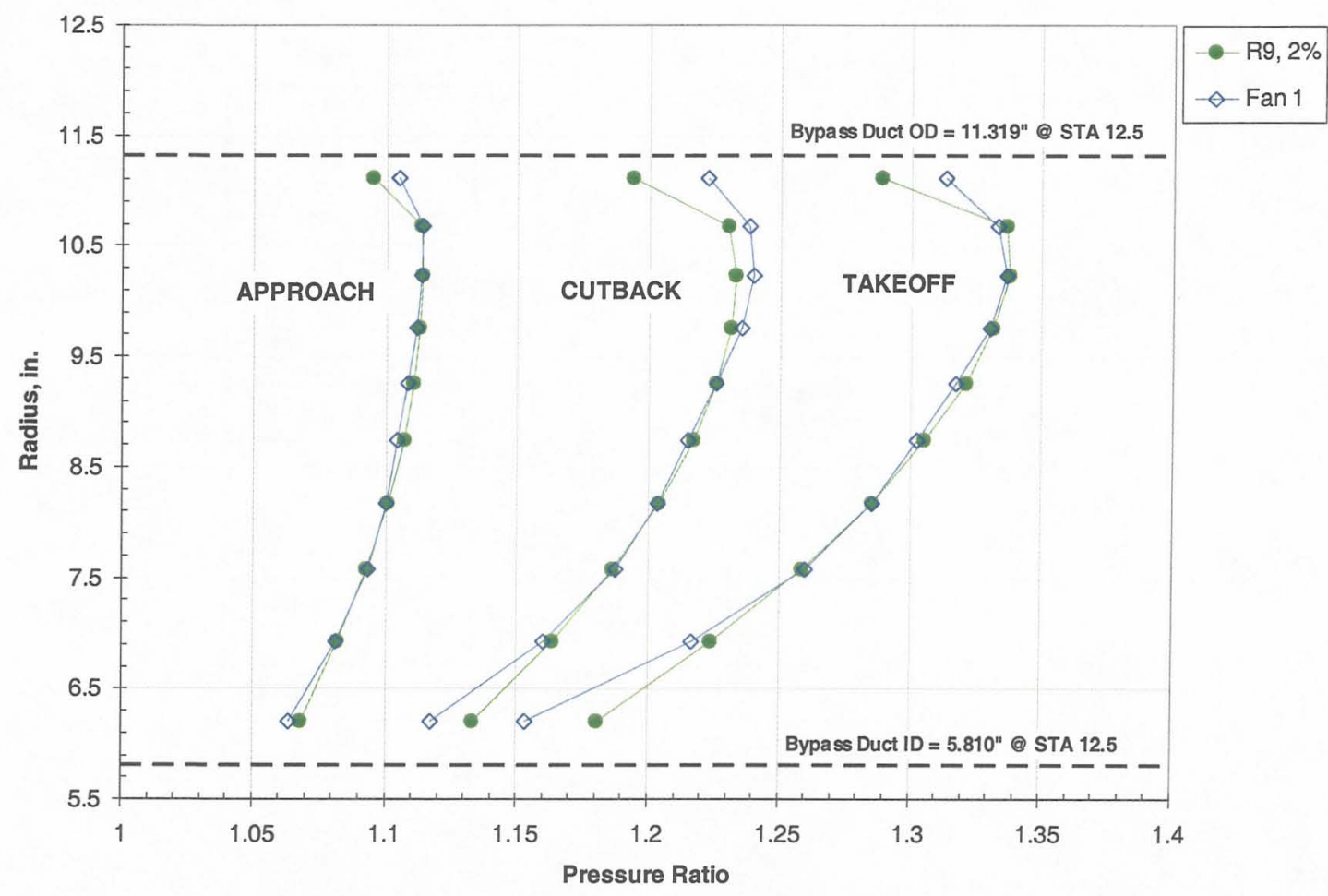

Fig. 10 Total pressure profile for Rotor 9 and Fan 1 


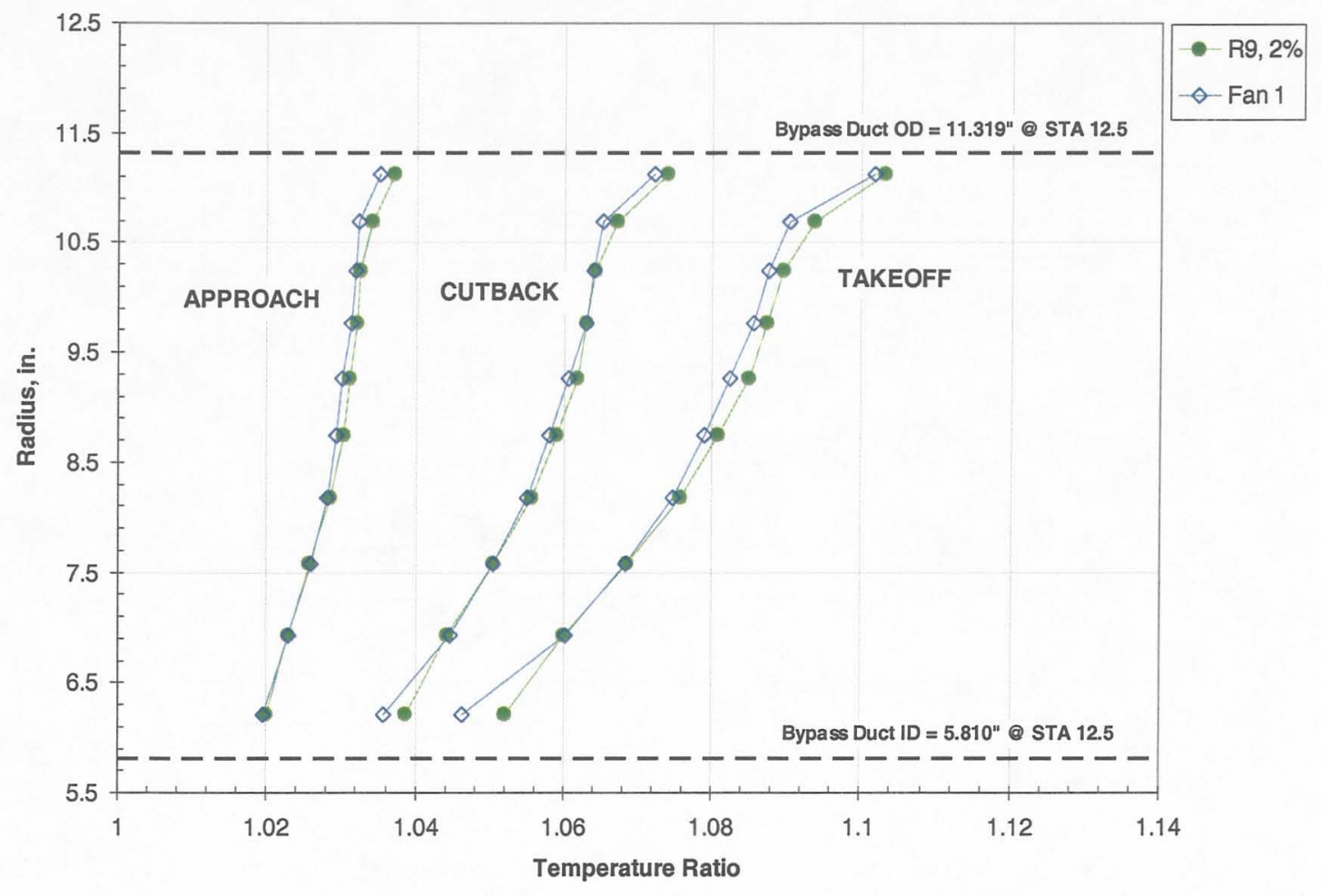

Fig. 11 Total temperature profile for Rotor 9 and Fan 1

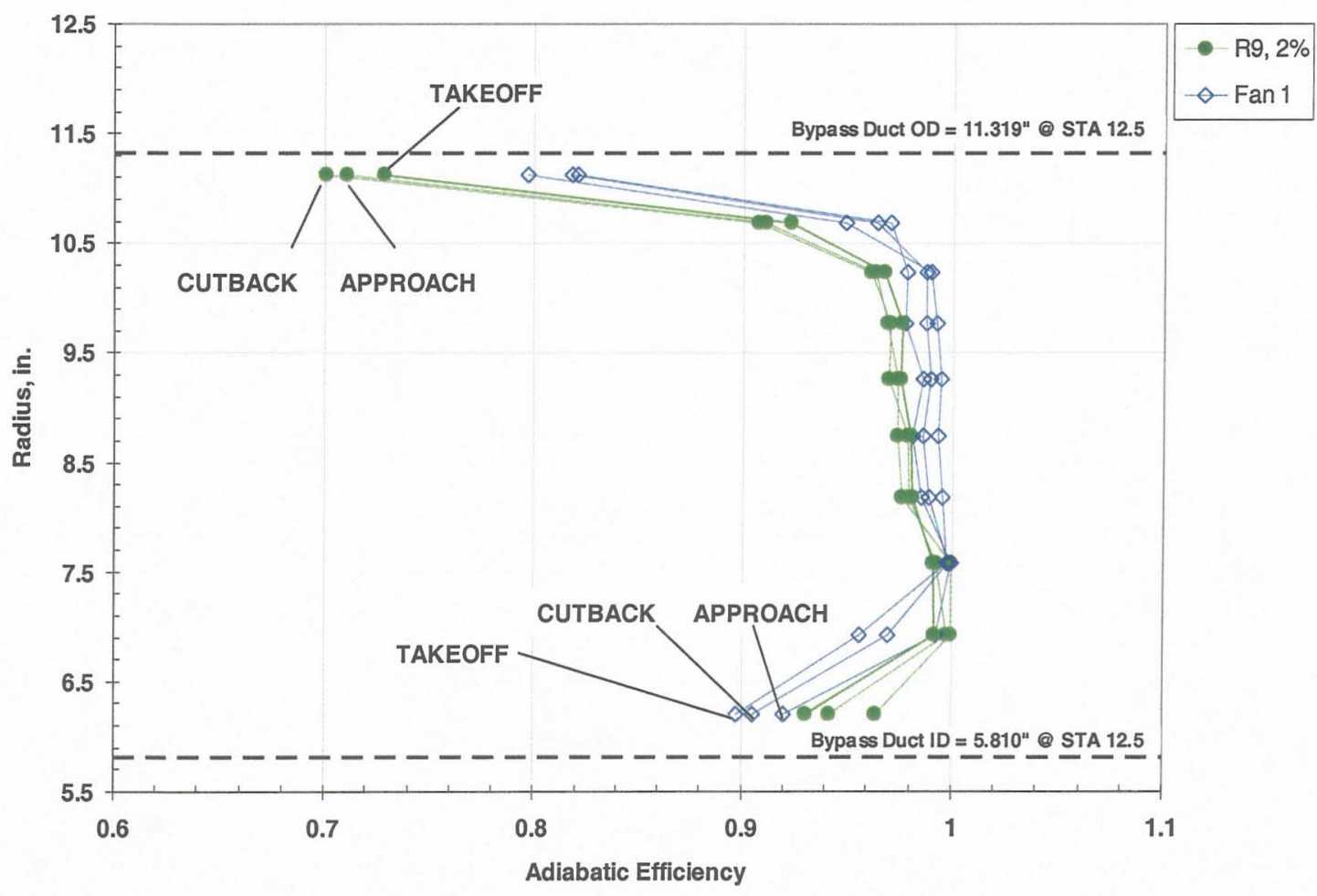

Fig. 12 Adiabatic efficiency profile for Rotor 9 and Fan 1 


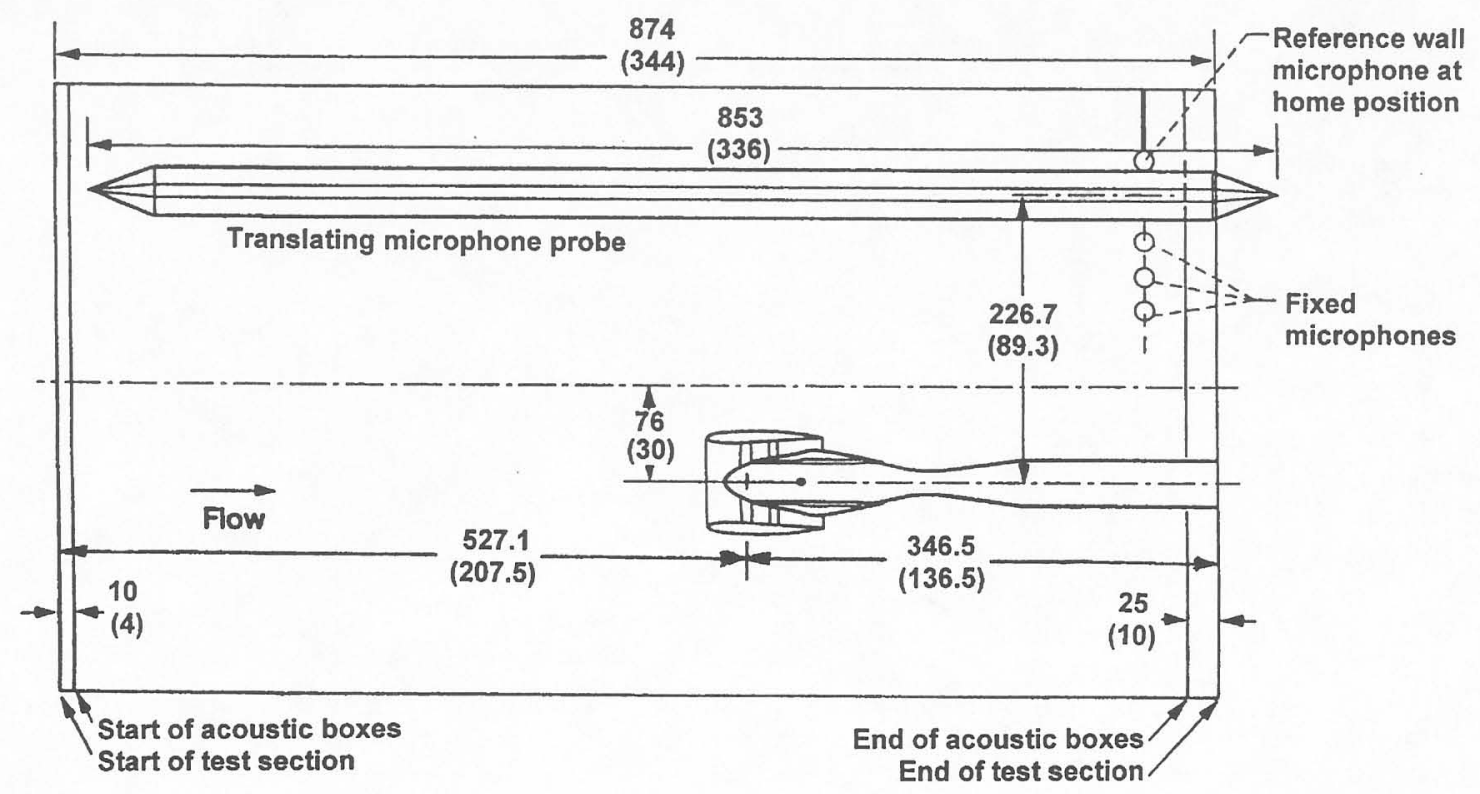

Fig. 13 Sketch of the model fan installed in the 9- by 15-Foot Low Speed Wind Tunnel. Far-field acoustic data were acquired with a translating microphone probe and aft fixed microphones. (Dimensions in $\mathrm{cm}$ (in.)).

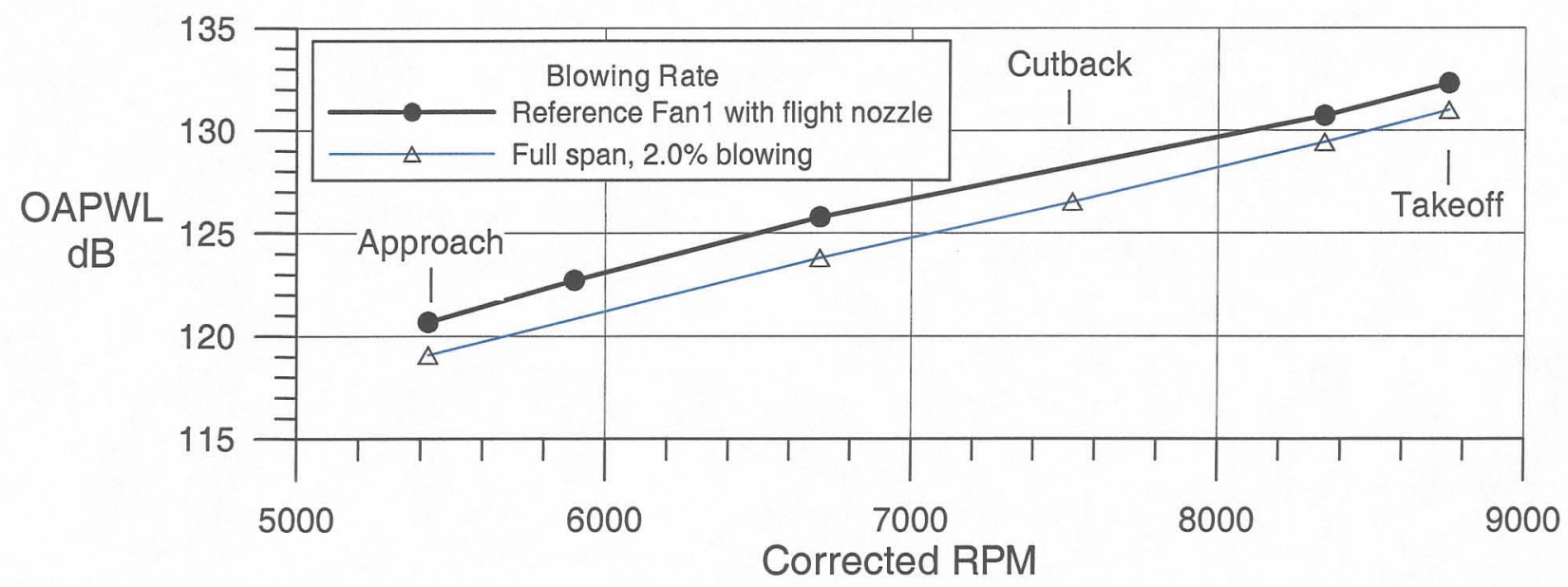

Fig. 14 Overall Sound Power Level as a function of corrected fan speed. 


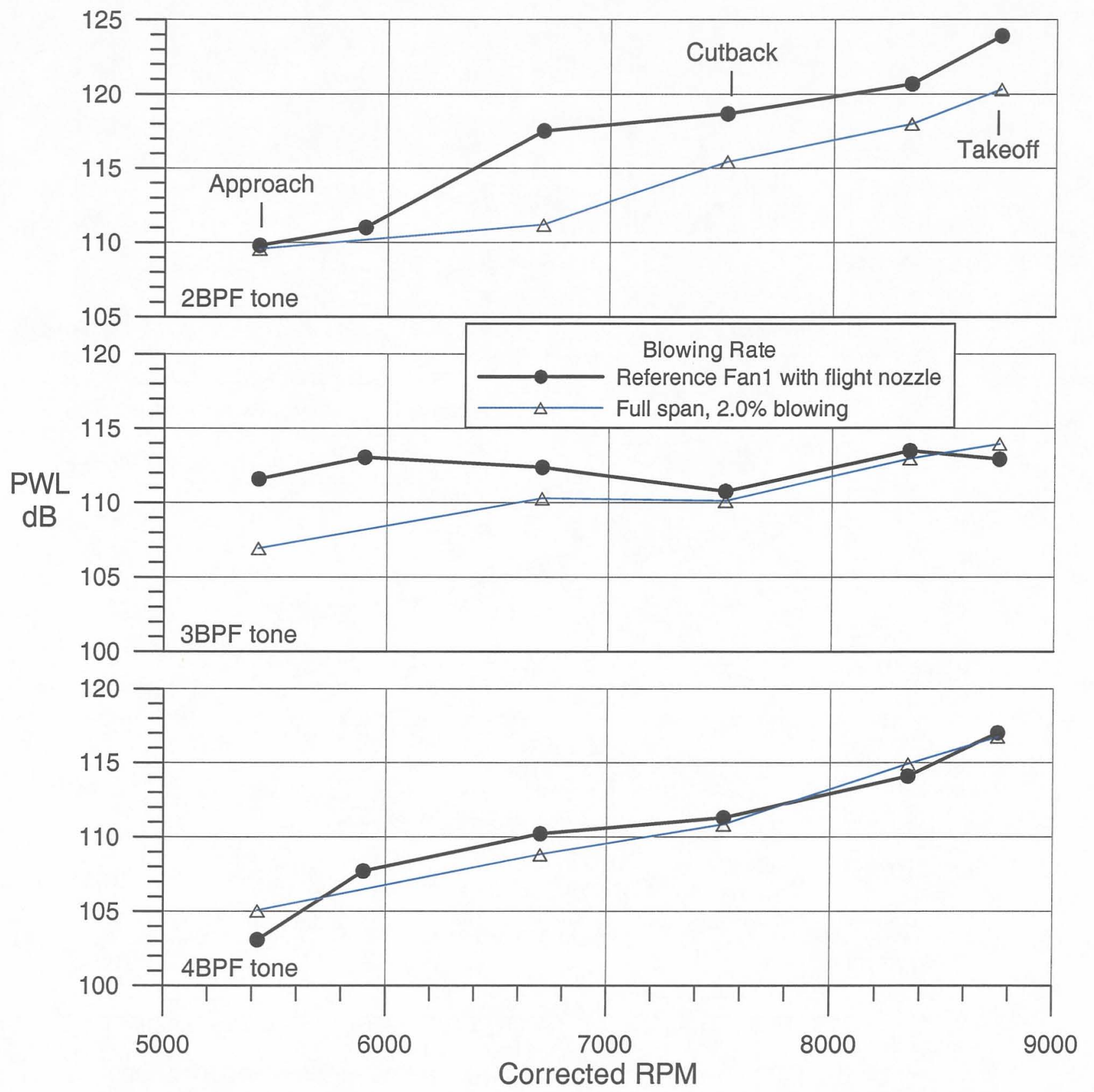

Fig. 15 Tone sound power level as a function of corrected fan speed ( $59 \mathrm{~Hz}$ bandwidth). 




Fig. 16 Constant $59 \mathrm{~Hz}$ bandwidth sound power level spectra showing benefits of rotor trailing edge blowing 


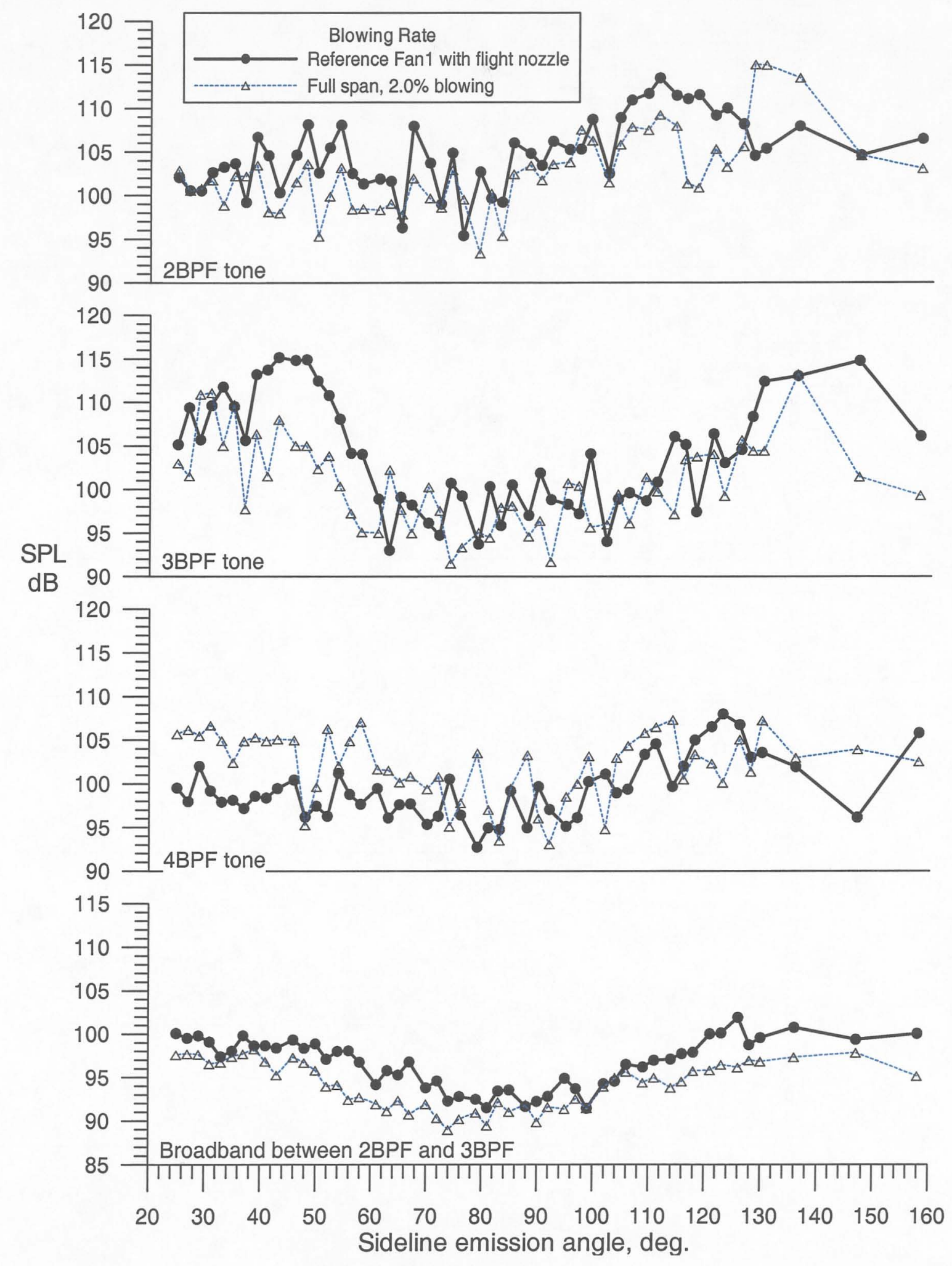

Fig. 17 Tone and broadband directivities at $5425 \mathrm{rpm}_{\mathrm{c}}(62 \%$ design fan speed, designated approach condition; directivities from $59 \mathrm{~Hz}$ constant bandwidth spectra). 


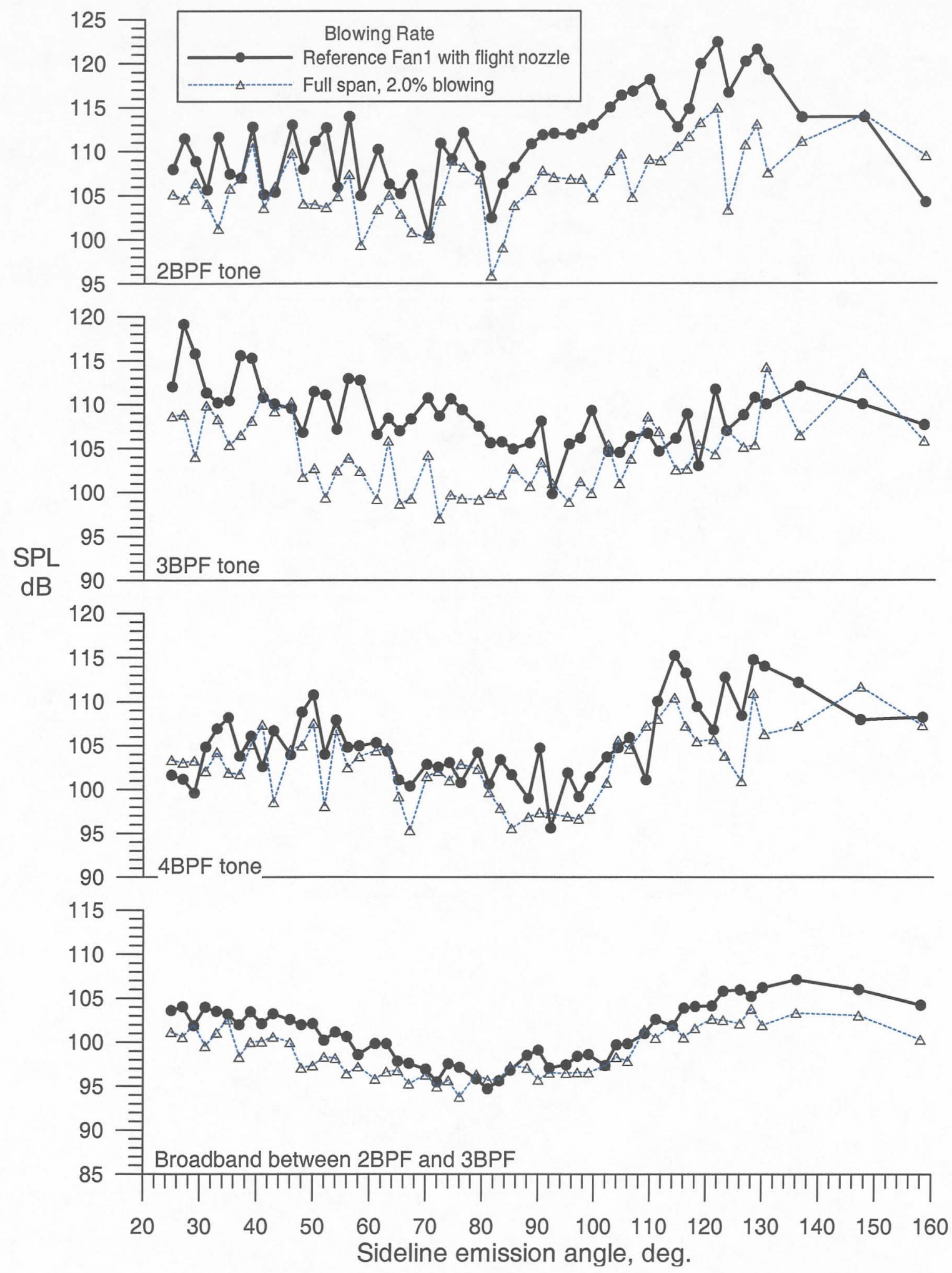

Fig. 18 Tone and broadband directivities at $6700 \mathrm{rpm}_{\mathrm{c}}(76.6 \%$ design fan speed, directivities from $59 \mathrm{~Hz}$ constant bandwidth spectra). 


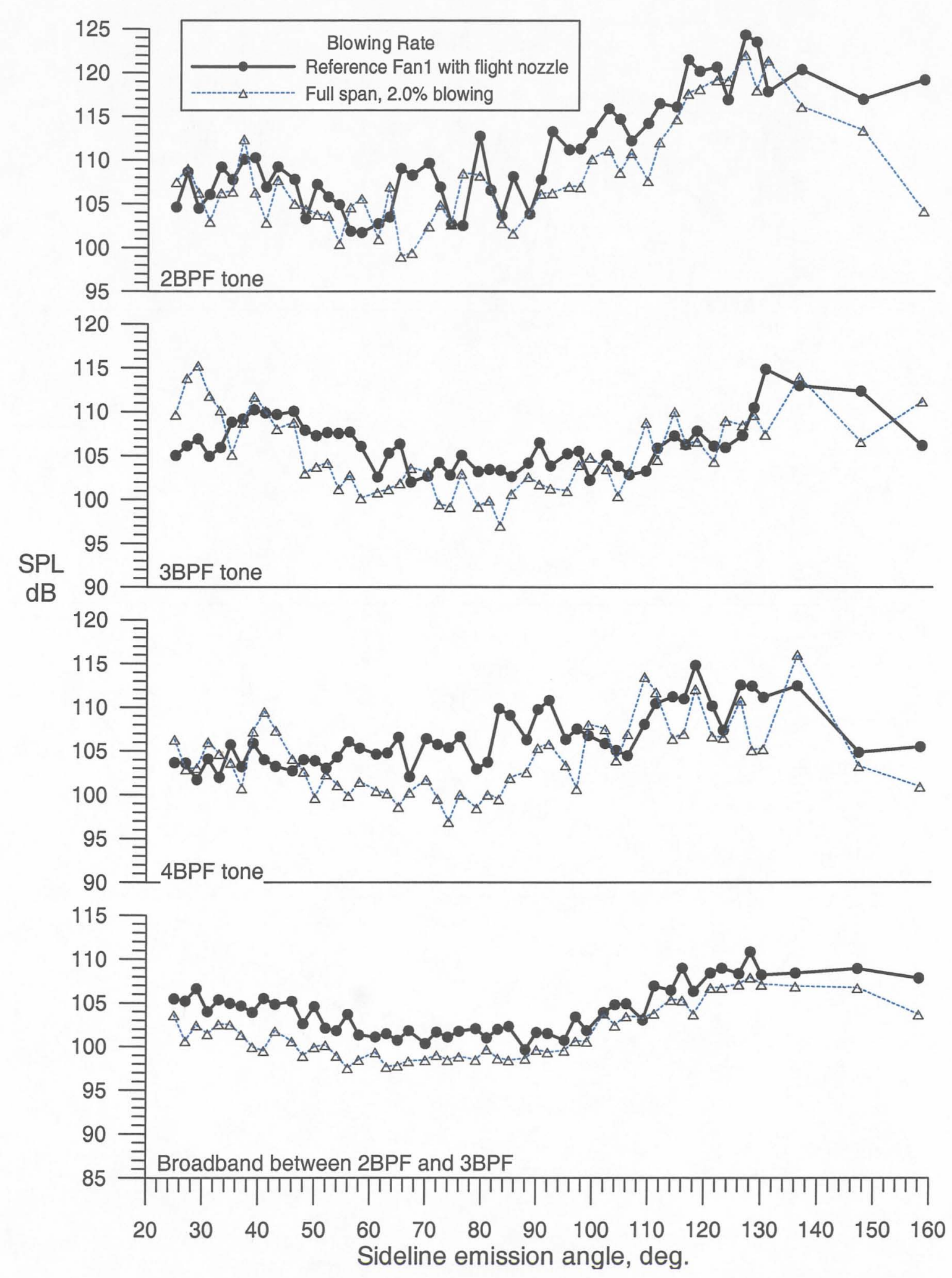

Fig. 19 Tone and broadband directivities at $7525 \mathrm{rpm}_{\mathrm{c}}(86 \%$ design fan speed, designated cutback condition; directivities from $59 \mathrm{~Hz}$ constant bandwidth spectra). 


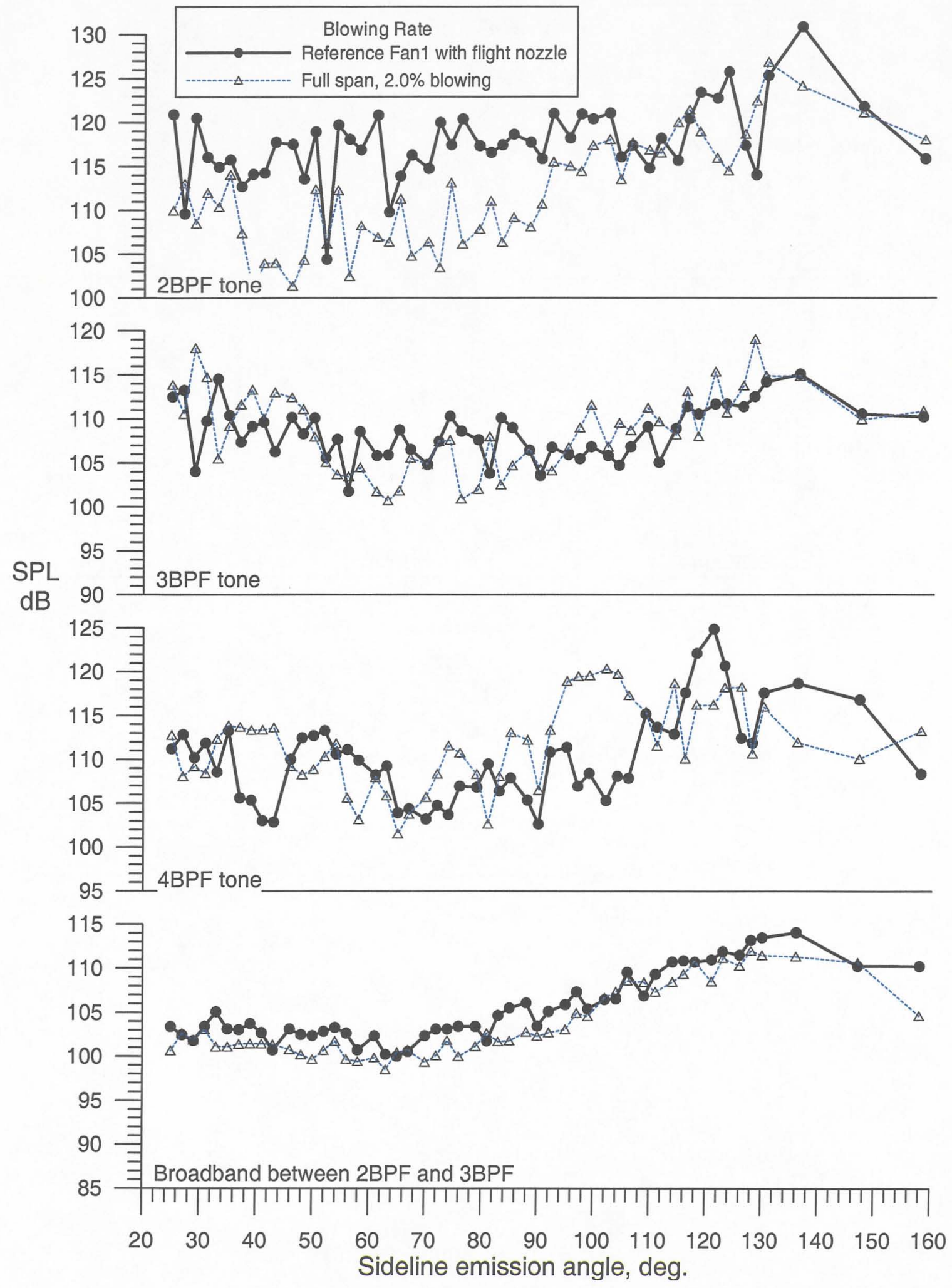

Fig. 20 Tone and broadband directivities at $8750 \mathrm{rpm}_{\mathrm{c}}(\mathbf{1 0 0 \%}$ design fan speed, designated takeoff condition; directivities from $59 \mathrm{~Hz}$ constant bandwidth spectra). 


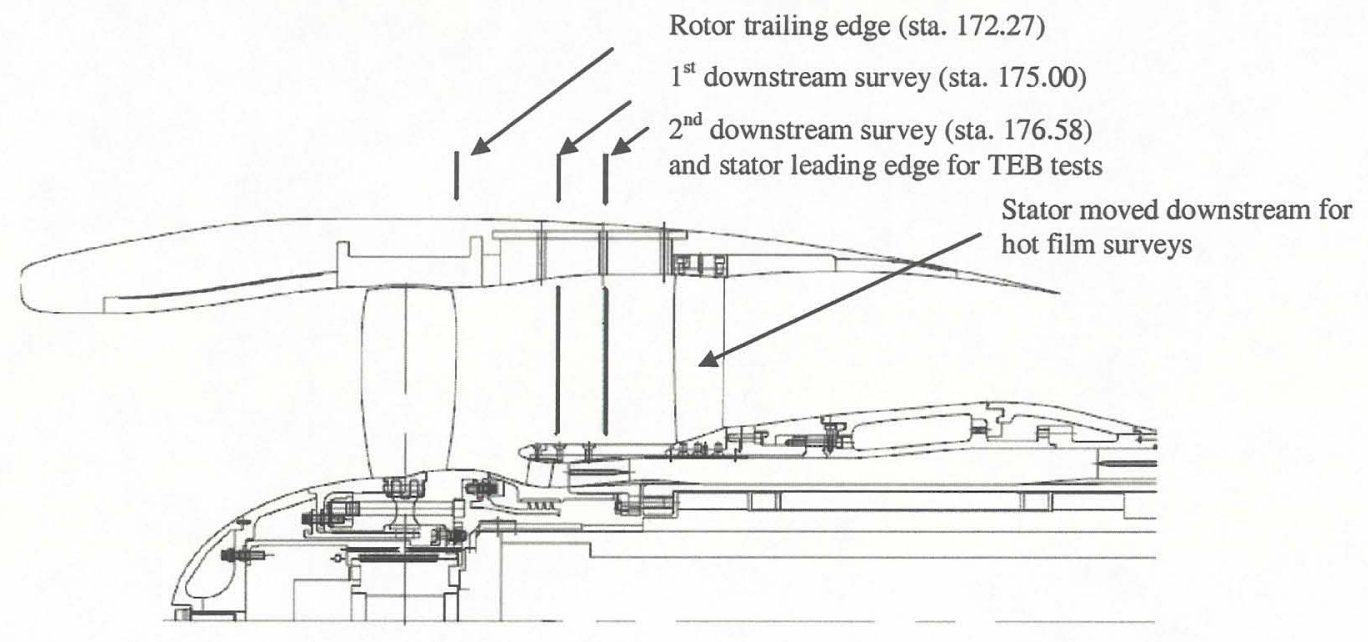

Fig. 21 Schematic illustrating location of hot-film surveys (station axial locations in inches).
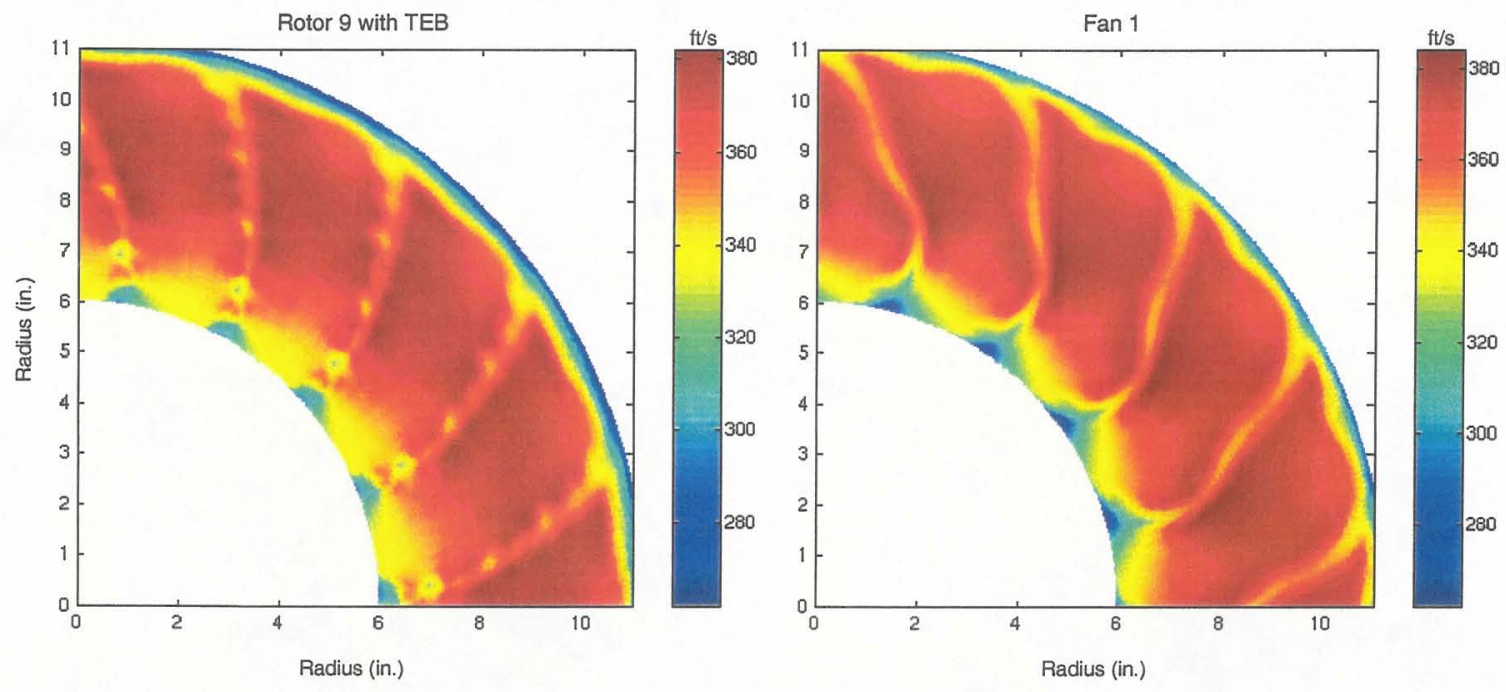

Fig. 22 Comparison of total velocity measured downstream of Fan 1 and Rotor 9 with TEB 

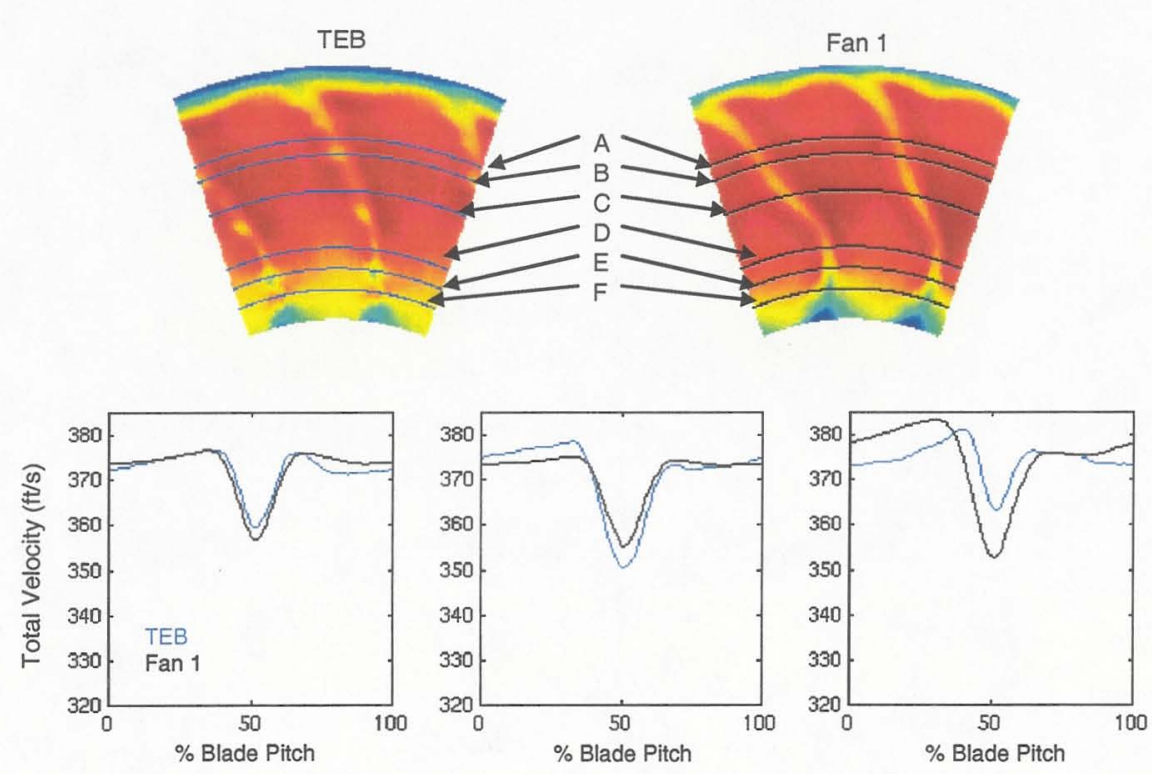

A) $r=9.74$

B) $r=9.42$

C) $r=8.67^{\prime \prime}$
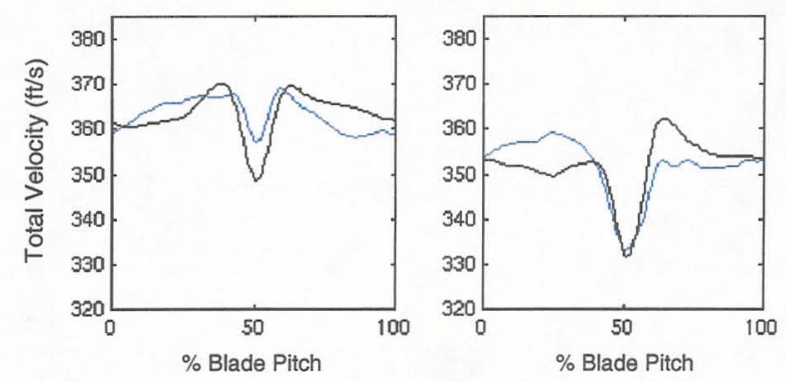

D) $r=7.49^{\prime \prime}$

E) $r=7 / 06^{\prime \prime}$

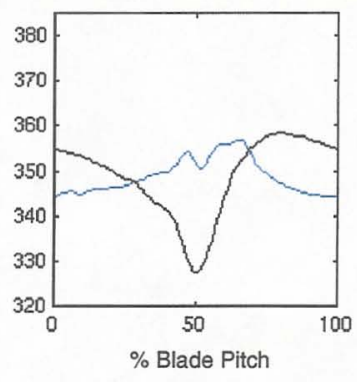

F) $r=8.63^{\prime \prime}$

Fig. 23 Comparison of blade wake total velocity profiles measured downstream of Fan 1 and Rotor 9 with TEB.
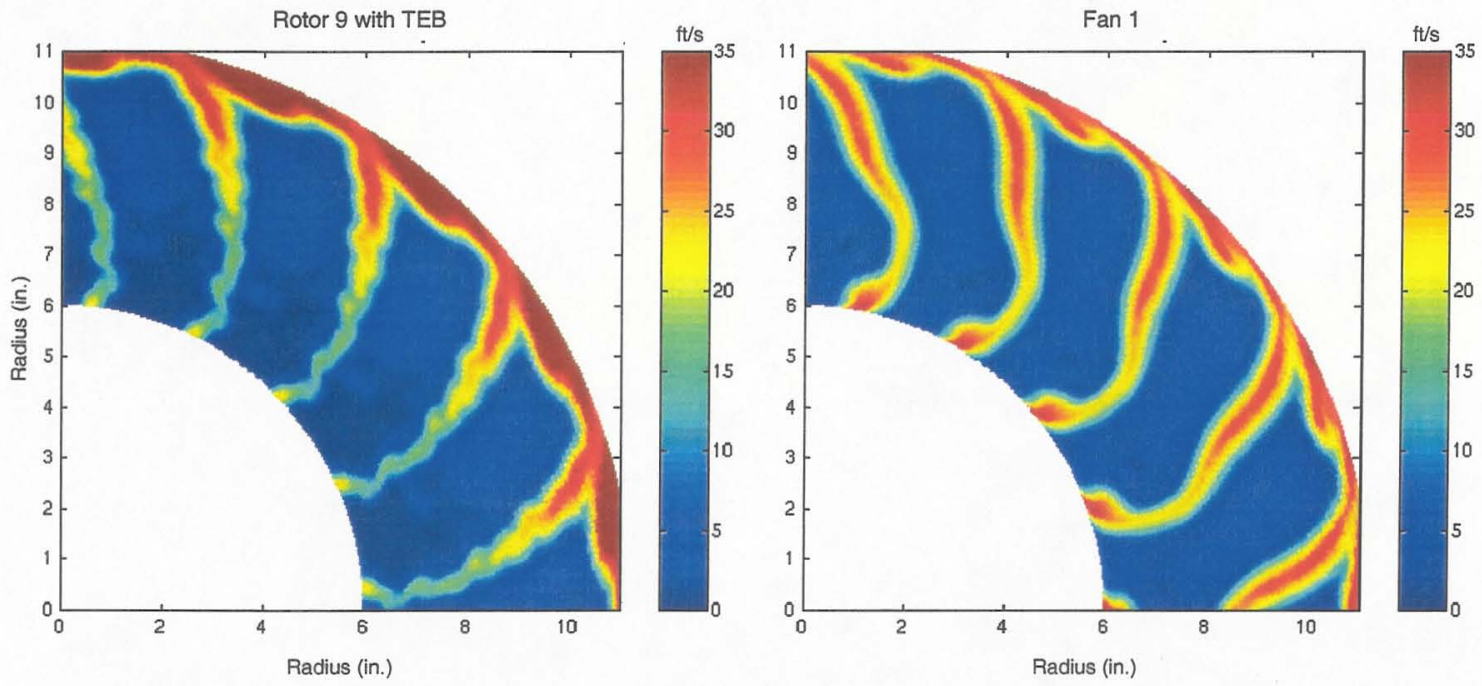

Fig. 24 Comparison of turbulent velocities measured downstream of Rotor 9 with TEB and Fan 1. 

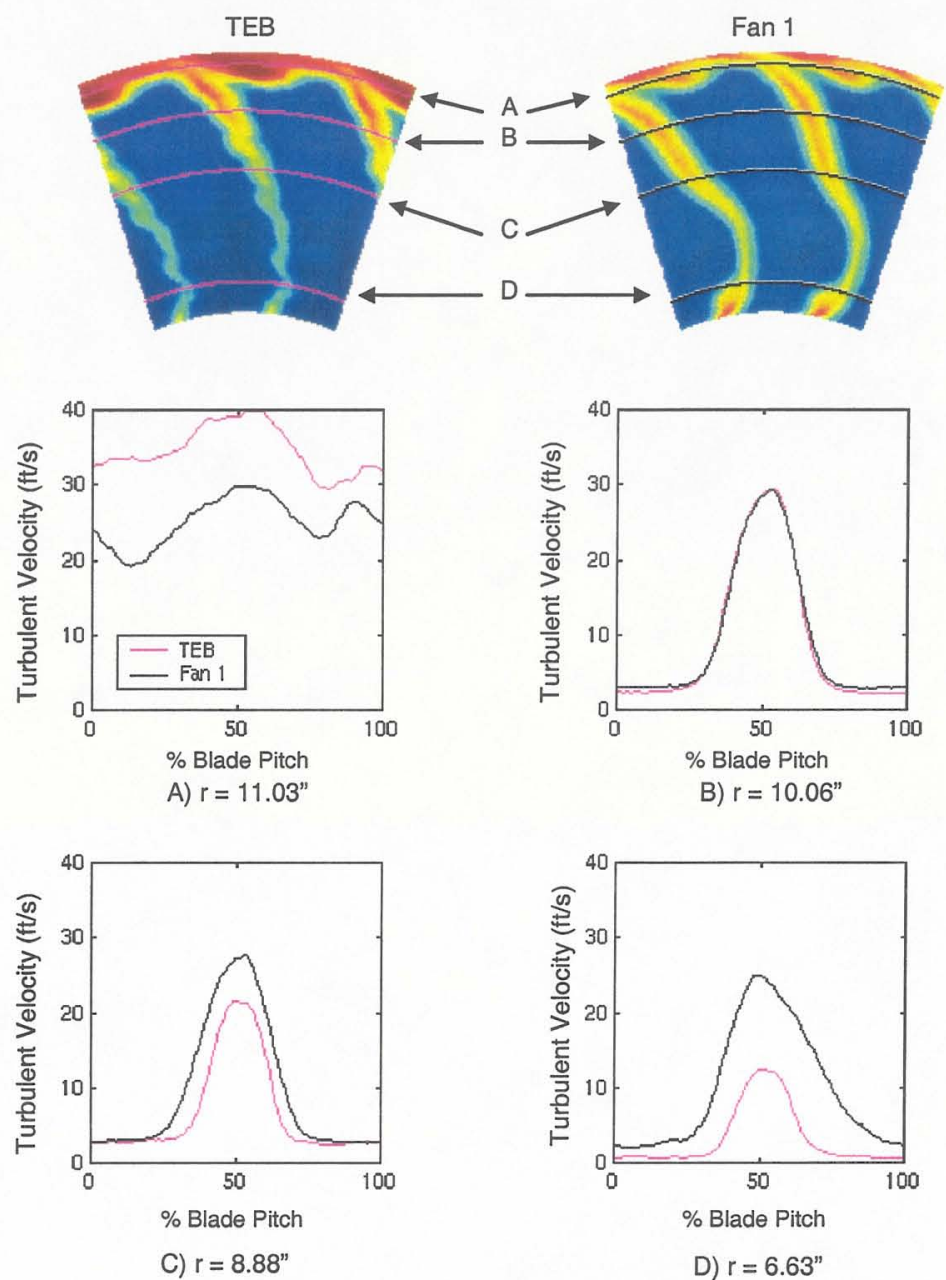

Fig. 25 Comparison of blade wake turbulent velocity profiles measured downstream of Fan 1 (black) and Rotor 9 with $2 \%$ TEB (magenta). 